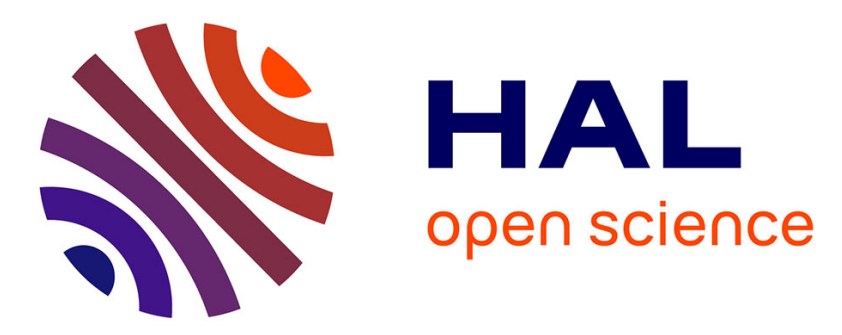

\title{
Role of frozen lubricant film on tribological behaviour and wear mechanisms in grinding
}

\author{
Eduardo Garcia, Damien Méresse, Iñigo Pombo, Mirentxu Dubar, José
}

Antonio Sánchez

\section{- To cite this version:}

Eduardo Garcia, Damien Méresse, Iñigo Pombo, Mirentxu Dubar, José Antonio Sánchez. Role of frozen lubricant film on tribological behaviour and wear mechanisms in grinding. International Journal of Advanced Manufacturing Technology, 2016, 82 (5-8), pp.1017-1027. 10.1007/s00170-015-7397-3 . hal-02098563

\section{HAL Id: hal-02098563 \\ https://hal.science/hal-02098563}

Submitted on 12 Apr 2019

HAL is a multi-disciplinary open access archive for the deposit and dissemination of scientific research documents, whether they are published or not. The documents may come from teaching and research institutions in France or abroad, or from public or private research centers.
L'archive ouverte pluridisciplinaire HAL, est destinée au dépôt et à la diffusion de documents scientifiques de niveau recherche, publiés ou non, émanant des établissements d'enseignement et de recherche français ou étrangers, des laboratoires publics ou privés. 
See discussions, stats, and author profiles for this publication at: https://www.researchgate.net/publication/279525293

\section{Role of frozen lubricant film on tribological behaviour and wear mechanisms in grinding}

Article in International Journal of Advanced Manufacturing Technology · June 2015 DOl: 10.1007/500170-015-7397-3

CITATIONS

5 authors, including:

Eduardo Garcia

University of Deusto

11 PUBLICATIONS 53 CITATIONS

SEE PROFILE

I. Pombo

Universidad del País Vasco / Euskal Herriko Unibertsitatea

44 PUBLICATIONS 501 CITATIONS

SEE PROFILE

Some of the authors of this publication are also working on these related projects:

Cilyndrical grinding research View project

Thermal diffusivity identification by 2 nd derivative analysis of transient temperature profile View project
68

Damien Meresse

University of Valenciennes and Hainaut-Cambresis

20 PUBLICATIONS 71 CITATIONS

SEE PROFILE

Mirentxu Dubar

University of Valenciennes and Hainaut-Cambresis 58 PUBLICATIONS 357 CITATIONS

SEE PROFILE 
ROLE OF FROZEN LUBRICANT FILM ON TRIBOLOGICAL BEHAVIOUR AND WEAR MECHANISMS IN GRINDING

\author{
E. García (1)*, D. Méresse (2), I. Pombo(1), M. Dubar (2), J.A. Sánchez(1) \\ (1) Dpt. Mechanical Engineering UPV/EHU. Almeda de Urkijo s/n, 48013-Bilbao, Spain. \\ (2) TEMPO EA 4542 Laboratory. UVHC - Carnot Arts Institute - 59300, Valenciennes, France \\ *Corresponding Author: phone: 34946017347 \\ e-mail: eduardojose.garcia@ehu.es
}

\begin{abstract}
In this paper the friction conditions of Minimum Coolant Grinding (MCG) technology are deeply characterized. The MCG is a successful cooling/lubricating system that combines the application of Minimum Quantity of Lubrication (MQL) and $\mathrm{CO}_{2}$ at low temperatures to create a frozen layer of oil able to reach the contact zone. This technique has previously shown promising results to reduce heat generation in grinding process and improve the workpiece finish. A comparison of the energy consumption, forces and wear patterns have been performed between MCG and dry grinding by means of the On-Machine Test Bench. In the work authors have identified that MCG favours the shearing of the material reducing the energy consumption and wear of the abrasive. Differences are highlighted on the size of wear flats, the shape of the debris and the various types of wear mechanisms
\end{abstract}


NOMENCLATURE

\begin{tabular}{|c|l|l|}
\hline Parameter & Name & Units \\
\hline$a$ & Depth of cut & $\mathrm{mm}$ \\
\hline$b$ & Workpiece thickness & $\mathrm{mm}$ \\
\hline$e_{c}$ & Specific grinding energy & $\mathrm{J} / \mathrm{mm}^{3}$ \\
\hline$F_{t}$ & Tangential force & $\mathrm{N}$ \\
\hline$F_{n}$ & Normal force & $\mathrm{N}$ \\
\hline$h_{e q}$ & Equivalent chip thickness & $\mathrm{mm}$ \\
\hline$I_{c}$ & Contact length & $\mathrm{mm}$ \\
\hline$P$ & Grinding power & $\mathrm{W}$ \\
\hline$Q_{w}$ & Material removal rate & $\mathrm{mm} / \cdot \mathrm{s}$ \\
\hline$Q_{w}{ }^{\prime}$ & Specific material removal rate & $\mathrm{mm} / \mathrm{mm} \cdot \mathrm{s}$ \\
\hline$V_{f}$ & Infeed speed & $\mathrm{mm} / \mathrm{min}$ \\
\hline$V_{s}$ & Grinding wheel speed & $\mathrm{m} / \mathrm{s}$ \\
\hline$V_{w}^{\prime}$ & Specific volume of part material removed & $\mathrm{mm} 3 / \mathrm{mm}$ \\
\hline$\mu$ & Friction index & - \\
\hline & & \\
\hline
\end{tabular}

\section{INTRODUCTION. STATE OF THE ART}

Grinding is an abrasive machining process commonly used for the production of high added-value components when high accuracy and smooth surfaces are needed. These requirements are typical of fields such as aeronautical, automotive, or energy generation. Wear of the abrasive grits has a direct influence on the quality of the final product. Not only roughness and tolerances are worsened when abrasive wear appears, but also the risk of thermal damage is increased. Grinding wheel dressing allows restoring the initial condition of the grits but as a counterpart the manufacturing time and the process costs of the process increase.

Therefore it is interesting to understand the interaction between the grinding wheel and the workpiece and its effect on wear. In the interaction between the grit and the workpiece three different material removing mechanisms have been identified in grinding [1]: rubbing, ploughing and shearing. Rubbing occurs when the uncut chip thickness is so small that the grit only causes elastic deformations in the material, as a consequence all the energy is lost in friction. Ploughing occurs when the penetration of the grains is increased and consists of the creation of grooves by plastic deformation but without removing material. Finally, shearing occurs when the penetration of the grit is further increased and the abrasive is able to create chips by shearing the material. Shearing is the most effective way of material removal, since most of the energy is consumed in cutting the material. 
These three mechanisms share a common characteristic: the interaction between the grit and the workpiece is dominated by sliding friction. Sliding friction is characterized by high tribological stress which locally involves elevated contact pressures and temperatures [2]. These extreme conditions cause the wear of the abrasive.

Three kinds of wear have been identified in grinding wheels: grain fracture, bond fracture, and attritious wear [3; 4]. Grain fracture is the failure of the grit according to the mechanisms described by [5] and [6]; that is, grain boundary micro-cracks and transgranular fracture within the Alumina grits. Bond fracture is the dislodging of complete abrasive grains as a consequence of binder failure. If these two wear mechanisms are not excessive they can be beneficial, since they lead to self-sharpening of the wheel.

Finally, attritious wear leads to the creation of wears flat areas that reduce grits cutting capacity and increase friction between the grit and the workpiece. This way the amount of heat generated raises, increasing, thus, the risk of thermal damage. Consequently, attritious wear is a non desired wear effect. Attritious wear appears as the consequence of chemical and mechanical effects greatly influenced by the extreme contact conditions above mentioned. From a mechanical point of view, plastic flow and crumbling of the grit caused by mechanical and thermal shocks have been identified [7]. From a chemical point of view, the affinity of iron oxides for $\mathrm{Al}_{2} \mathrm{O}_{3}$ is magnified by high temperatures and the reactions between the workpiece and the abrasive material reduce the grit mechanical resistance [7].

In addition, adhesion of workpiece material to the abrasive grits must be taken into account since it leads to the lost of grits cutting capacity. Adhesion is the creation and breakage of atomic links between the contact materials that can be reduced by a proper lubrication of the contact.

The classic way to reduce the effects of friction in grinding, namely wear and heat generation is the use of cutting fluids. Their main roles are to improve lubrication so that the effect of friction, wear, and adhesion are reduced, to extract heat from the contact area and cool down the workpiece, and to clean the wheel from chips and debris of the process [8]. In order to achieve their role, it is very important that lubricants penetrate the contact zone. However, cutting fluids used nowadays do not completely fulfil these requirements. On the one hand, only a small quantity of the cutting fluid reaches the abrasive-workpiece interface. According to [9], only between the 5 and $20 \%$ of the total fluid supplied reaches contact zone. On the other hand, water based emulsions act as catalyst of chemical reactions that generate wear flats [10]. The alternative of vacuum grinding that would prevent these chemical reactions is avoided because the adhesion between nascent steel chips and abrasive becomes more important [11]. 
This way, although there are still research works oriented to improve the performance of traditional fluids [12], the strongest effort is devoted to find alternative solutions for traditional grinding fluids. Liquid nitrogen has been used for cryogenic grinding [13], however its industrial applications are limited by its cost. The use of compressed cold air is a cheaper alternative [14] nevertheless its poor cooling capacity does not fulfil grinding requirements. A further step is the use of the Minimum Quantity of Lubrication (MQL) technique [15]. The MQL supplies the oil as aerosol suspended in pressurized air. This technique has been successfully implemented in machining processes such us turning or milling [16], however, its reduced cooling capacity limits its application in grinding. Therefore, efforts are oriented to improve effect of MQL. In [17] the lubricating effect of MQL was improved by the addition of oil based nanolubricants, which helped reducing tool wear, energy consumption and the frictional losses at the wheel-workpiece interface.

Based on MQL technique, the Minimum Coolant Grinding (MCG) technology was developed in [18]. It consists of using liquid $\mathrm{CO}_{2}(191 \mathrm{~K})$ to freeze the MQL oil drops over the surface of the wheel. This way a protective layer of frozen oil is created able to reach the contact zone, improving lubrication, and protection of the grits. Despite the successful results obtained, the high oil and $\mathrm{CO}_{2}$ consumptions limited its industrial implementation. Therefore in [19] high freezing point oils, specially designed for the process, were used in order to reduce consumptions. Results showed that not only were oil and $\mathrm{CO}_{2}$ consumptions efficiently reduced, but also process performance was improved when compared to conventional cooling in terms of energy consumption and wheel wear.

The mentioned study [19] was developed under industrial conditions; however, a scientific explanation for the effect of MCG in the contact is not available yet. Therefore, this paper is aimed at studying in detail the effect of the MCG in the contact. A tribological study of the mechanisms involved in the improved performance of the MCG technique is presented. The study is based on the analysis of process forces, friction index, energy consumption, and microscope observations of the worn abrasive when comparing dry grinding and MCG grinding in the On-Machine Test Bench [20].

After the bibliographic revision presented in this Section, the experimental methodology is described in Section 2, which includes both the description of the experimental apparatus as well as the set of tests developed. Results of the tests in terms of specific grinding energy, process forces and friction index are analyzed in Section 3. In this section optical and SEM observation of the abrasive surface after the tests are also analysed. 


\section{EXPERIMENTAL METHODOLOGY}

The experimental work has been developed in a test bench especially designed for the study of the frictional conditions in grinding: On-Machine Test Bench [20]. It is based on a horizontal-spindle CNC surface grinding machine where a cup grinding wheel removes material from a steel plate with a constant infeed speed, as it can be seen in Figure 1.

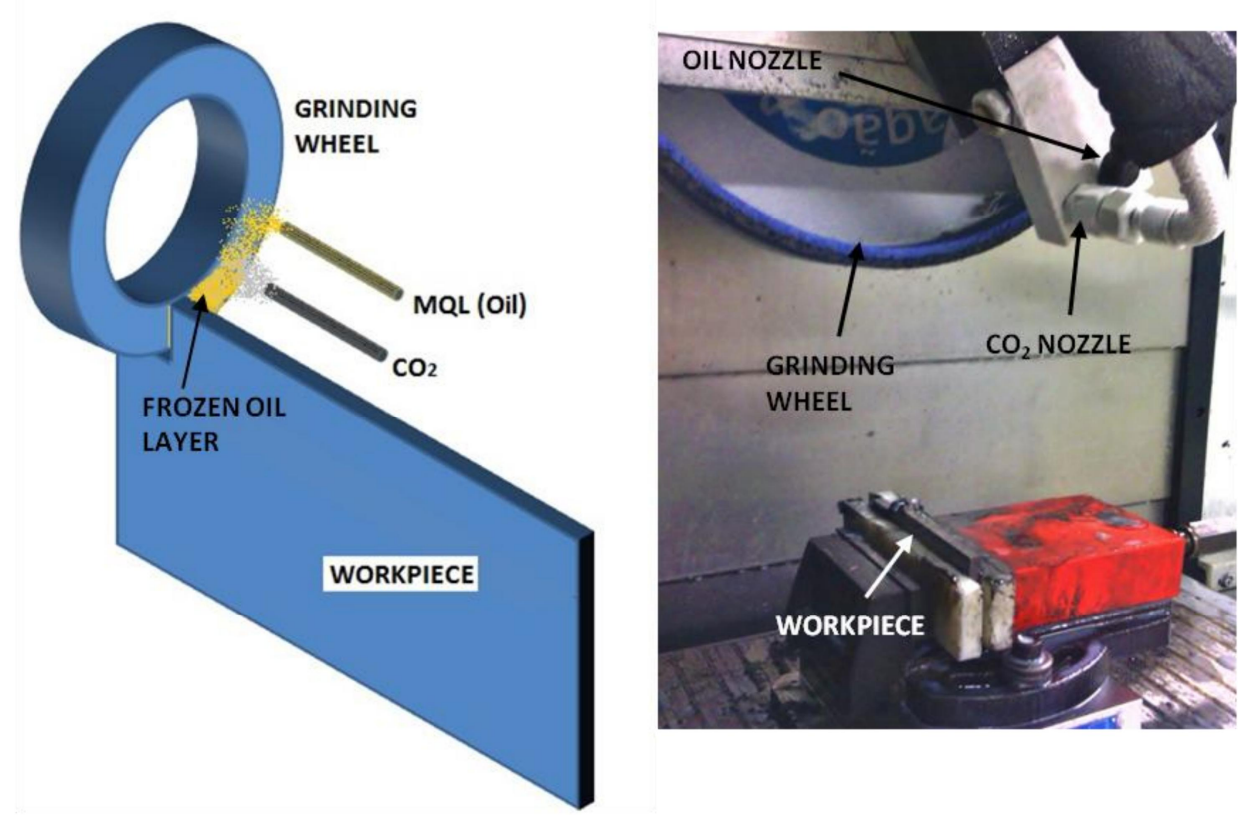

Figure 1. Test bench schema showing the different components and real layout.

This experimental configuration differs from typical grinding tests developed in grinding machines and has been chosen since it presents some advantages for the present study. In the direction of the spindle axis the configuration is very rigid, so that the effect of machine deformations can be neglected and an accurate control of the depth of cut and chip thickness is achieved. The contact length is known and constant at every moment since it coincides with the width of the workpiece. Therefore, the error in the determination of the contact area can be neglected.

The use of already known configurations for tribological studies, such as X-on-disk, was rejected because they were not able to reproduce the high local contact pressures $(2 \mathrm{Gpa})$ and relative speeds $(40 \mathrm{~m} / \mathrm{s})$ of grinding processes.

The test bench is fitted with a 3D load sensor (Kistler 9257B), and a power meter device Load Controls Inc. UPC-FR installed on the wheel spindle which allow measuring process forces and power consumption during the tests. Then the specific grinding energy, $e_{c}$, and the friction index, $\mu$, can be obtained according to eq. 1 and eq. 2 [21]: 
$e_{c}=\frac{P}{Q_{w}}=\frac{F_{t} \cdot v_{s}}{v_{f} \cdot l_{c} \cdot a_{e}}$

$\mu=F_{t} / F_{n}$ eq.1

eq. 2

The test bench allows controlling the infeed speed of the wheel into the workpiece, $v_{f}$. In order to relate this infeed speed to the parameters of an actual grinding operation, the equivalent chip thickness, $h_{e q}$, and the specific material removal rate, $Q^{\prime}{ }_{w}$ have been used [20]:

$Q^{\prime}{ }_{W}=I_{c} \cdot V_{f}$

eq. 3

$h_{e q}=Q^{\prime}{ }_{w} / v_{s}$

eq. 4

Test parameters have been gathered in Table 1. For each cooling condition two conditions have been tested. The first one corresponds to very low $Q^{\prime}{ }_{\text {w }}$ values, met in practical grinding finishing operations. This value has been chosen in order to assess the effect of very low grain-workpiece interaction, representative of ploughing conditions. The conditions of Test 2 corresponds to $Q^{\prime}{ }_{w}$ characteristic of semi-finishing grinding operations, where shearing becomes predominant.

As mentioned, the lubricating and protective effect of the MCG should reduce the wear of the abrasive grits. Taking into account that wear of abrasive particles is a slow process long grinding tests without intermediate dressings have been performed. For each test the same specific volume of part material $\left(V_{w^{\prime}}\right)$ was removed: $125 \mathrm{~mm}^{3} / \mathrm{mm}$. This was long enough for identifying abrasive wear effects.

\begin{tabular}{|c|c|c|c|c|c|c|}
\hline $\begin{array}{l}\text { Cooling } \\
\text { Condition }\end{array}$ & Test & $\begin{array}{c}Q_{w}^{\prime} \\
{\left[\mathrm{mm}^{3} / \mathrm{mm}\right.} \\
\mathrm{s}]\end{array}$ & $h_{e q}[\mathrm{~nm}]$ & $\begin{array}{c}v_{f} \\
{[\mathrm{~mm} / \mathrm{min}]}\end{array}$ & $v_{s}[\mathrm{~m} / \mathrm{s}]$ & $\begin{array}{c}V_{w}^{\prime} \\
{\left[\mathrm{mm}^{3} / \mathrm{mm}\right]}\end{array}$ \\
\hline \multirow{2}{*}{ DRY } & Test 1 & 0.17 & 7 & 2 & 24 & 125 \\
\hline & Test 2 & 0.42 & 18 & 5 & 24 & 125 \\
\hline \multirow{2}{*}{ MCG } & Test 1 & 0.17 & 7 & 2 & 24 & 125 \\
\hline & Test 2 & 0.42 & 18 & 5 & 24 & 125 \\
\hline
\end{tabular}

Table 1. Experimental work description. These tests have been repeated with two grinding wheels: 2A46I8VWEB2 (AL) and 30SA46I8VWEB2 (SG).

Once the test is completed samples are extracted from the wheel to perform observations of the worn surfaces. Then one new wheel is necessary for each test. Finally optical microscope and scanning electron microscope (SEM) observations 
of the worn surface of the wheel are performed. The observations are completed with EDX analysis for identification of components.

The workpiece used during the test is a rectangular plate $(100 \times 45 \times 5 \mathrm{~mm})$ made of AISI4140 steel (hardened at 56HRC) clamped to the machine bench by means of Teflon plates.

The influence of abrasive type has also been studied. For this purpose tests presented in Table 1 have been repeated for white fused alumina (AL = 2A46I8VWEB2) and for "ceramic" Sol-Gel type alumina (SG = 30SA46I8VWEB2) [22].

As it can be deduced from the specification both grinding wheels have a similar configuration in terms of grit size, porosity and structure but differ in the type of abrasive. The Sol-Gel process allows obtaining a finer crystalline structure from a submicron narrowly sized powder [7]. This significantly improves the grain hardness and toughness.

\section{RESULTS AND DISCUSSION}

Dry grinding and MCG grinding performances are compared in terms of energy consumption, and friction index. Afterwards, optical and SEM observations of the wheel worn surfaces are used to demonstrate the differences in the tribological behaviours of MCG and Dry grinding.

\subsection{Specific Grinding Energy}

The specific grinding energy, $e_{c}$, gives information on the efficiency of the process, since it is the energy needed for removing the volumetric unit of part material. High values of $e_{c}$ are related to contact mechanisms different from shear such as rubbing or ploughing.

Figure 2 and Figure 3 show the specific energy consumption as a function of specific volume of part material removed, $V_{w}{ }^{\prime}$, in Dry and MCG grinding. Figure 2 corresponds to low values of $h_{e q}$ (Test 1), while Figure 3 to medium values of $h_{e q}$ (Test 2). In the figures the results for both grinding wheels tested are shown: SG, continuous lines, and AL, dashed lines.

Generally, it can be seen that MCG is more efficient than Dry grinding. In Figure 2 (Test 1) energy consumed in MCG grinding is noticeably lower than in Dry grinding: $150 \mathrm{~J} / \mathrm{mm}^{3}$ (MCG) and $290 \mathrm{~J} / \mathrm{mm}^{3}$ (Dry) at the beginning of the test, which is a reduction close to $50 \%$. This difference of about $150 \mathrm{~J} / \mathrm{mm}^{3}$ is maintained during the whole test. The lubricating effect of the frozen layer of oil is responsible for the improved performance of MCG 


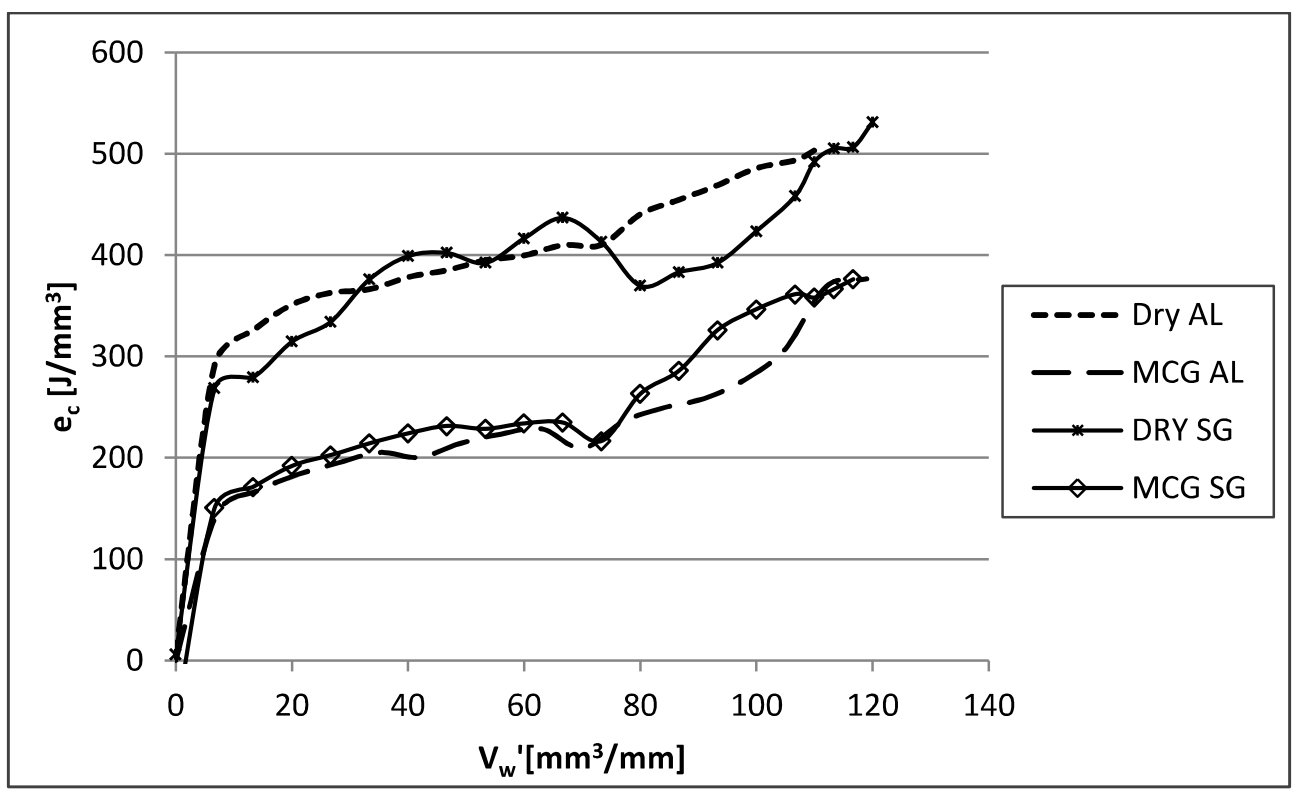

Figure 2. Comparison of $e_{c}$ consumption for MCG and Dry grinding in Test 1. $\mathrm{Q}^{\prime}=0.17 \mathrm{~mm}^{3} / \mathrm{mm} \cdot \mathrm{s}, h_{e q}=7 \mathrm{~nm}$

When the penetration of the abrasive grit into the workpiece is increased, as it is the case of Test $2\left(h_{e q}=18 \mathrm{~nm}\right)$, the improved lubrication of the oil frozen layer created by the MCG technology results in a more efficient process. However, in this case the difference between MCG and Dry grinding is lower. Using the frozen lubricant induces a decrease of the specific energy between 20 and $50 \mathrm{~J} / \mathrm{mm}^{3}$ in Test 2, far from the $150 \mathrm{~J} / \mathrm{mm}^{3}$ of the Test 1 . The different material removing mechanisms that prevail in each condition will explain this difference between Test 1 and Test 2.

At the low values of equivalent chip thickness of the conditions of Test 1 the abrasive grit slightly penetrates the material, being ploughing and rubbing the predominant mechanisms in the contact. The part of the energy consumed by friction in these conditions is relevant and a reduction of friction provided by the improved lubrication of the MCG system clearly reduces the overall energy consumption. By contrast when equivalent chip thickness is higher (Test $2, h_{e q}$ $=18 \mathrm{~nm}$ ) the penetration of the grit in the material rises as well. Under these conditions the abrasive is able to remove material by shearing, which is a much more efficient material removing mechanism than ploughing and rubbing. Consequently, the fraction of energy consumed by friction is smaller and, thus, the improvement obtained by a better lubrication is less evident. 


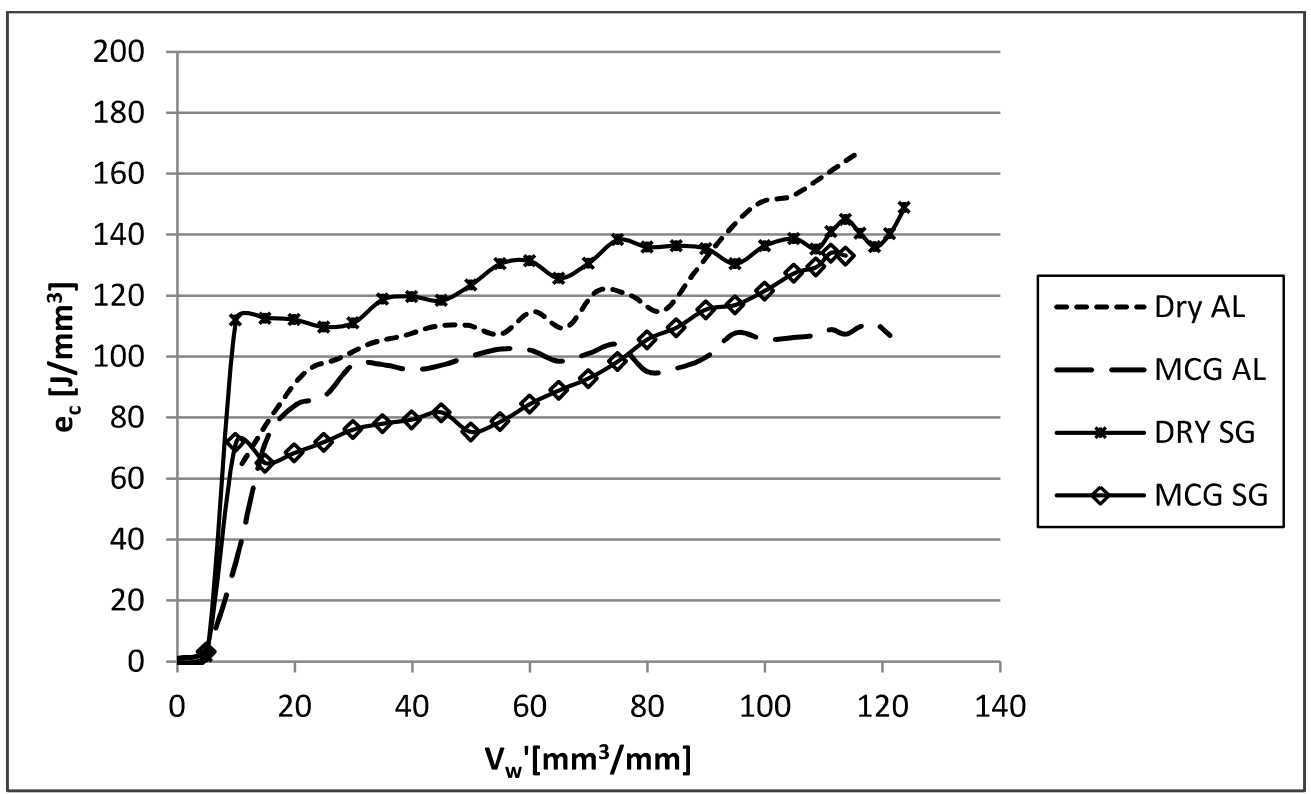

Figure 3 Comparison of $e_{c}$ consumption for MCG and Dry grinding in Test 2 conditions. Q'= $0.42 \mathrm{~mm}^{3} / \mathrm{mm} \cdot \mathrm{s}, h_{e q}=18 \mathrm{~nm}$

From the three mechanisms of sliding friction that characterize grinding, i.e., adhesion, plastic deformation and furrowing (Section 1) the improved lubrication is supposed to reduce adhesion and plastic deformation. This hypothesis should be confirmed with the analysis of forces results (Section 3.2) and worn surfaces observations (Section 3.3).

Another important aspect to point out from Figure 2 and Figure 3 is the size effect, which is the reduction of specific energy as the depth of cut is increased. This effect is clearly recognizable in Tests 2 where $h_{e q}$ is greater than in Test 1 and the mean $e_{c}$ values (around $100 \mathrm{~J} / \mathrm{mm}^{3}$ ) are smaller than those of Test 1 (around $300 \mathrm{~J} / \mathrm{mm}^{3}$ ).

On Figure 2 and Figure 3 an increase of $e_{c}$ consumption is also observable as the test progresses. The total increase of $e_{c}$ in the conditions of Test 2 is smaller than in Test 1: around $100 \mathrm{~J} / \mathrm{mm}^{3}$ in the worst case compared to $200 \mathrm{~J} / \mathrm{mm}^{3}$. Taking into account the relationship between $e_{c}$ increase and wear of abrasive, these results mean that in Test 2 the abrasive grits stand attritious wear much better than in the case of Test 1. According to [11] this increase is due to the energy consumed in sliding and is attributed to the effect of rubbing. Sliding appears due to the loss of cutting capacity of the grits. Malkin explains that just after dressing grinding energy is mainly consumed in ploughing and shearing the material. As long as the grits remove material and loss cutting capacity there is a part of the energy which is consumed in sliding. Since the energy consumed in ploughing and shearing does not significantly vary, the increase in sliding energy causes the overall energy consumption to rise. The loss in cutting capacity is due to two main factors: wear flat areas generation as a consequence of attritious wear and loading of the wheel with the material removed from the workpiece. 
Finally, regarding the influence of the type of alumina, the comparison of the performance of the different wheels (Fused alumina vs. Sol-gel alumina) does not show remarkable differences in these conditions. It means that the improvement obtained with MCG system does not depend on the abrasive type.

\subsection{Forces and Friction Index}

In Figure 4 and Figure 5 normal forces as a function of specific volume of part material removed, $V_{w}{ }^{\prime}$, are plotted for Test 1 and Test 2. Figure 4 correspond to Dry grinding and Figure 5 to MCG grinding.

In Figure 4 it can be observed that in Dry grinding normal forces decrease with the increase of the equivalent chip thickness. The normal force reaches a maximum of $90 \mathrm{~N}$ with $h_{e q}=7 \mathrm{~nm}$ (Test 1 ), while the maximum normal force is of $50 \mathrm{~N}$ for AL and $60 \mathrm{~N}$ for SG in Test $2\left(h_{e q}=18 \mathrm{~nm}\right)$. This is due to the better indentation of the grit in the material when the equivalent chip thickness is increased. At low depths of cut when ploughing is predominant the grit hardly penetrates the material, and pushes it as the wheel advances causing plastic deformation and high normal forces. By contrast, when the depth of cut is increased shearing takes over and the material is removed easily reducing normal forces.

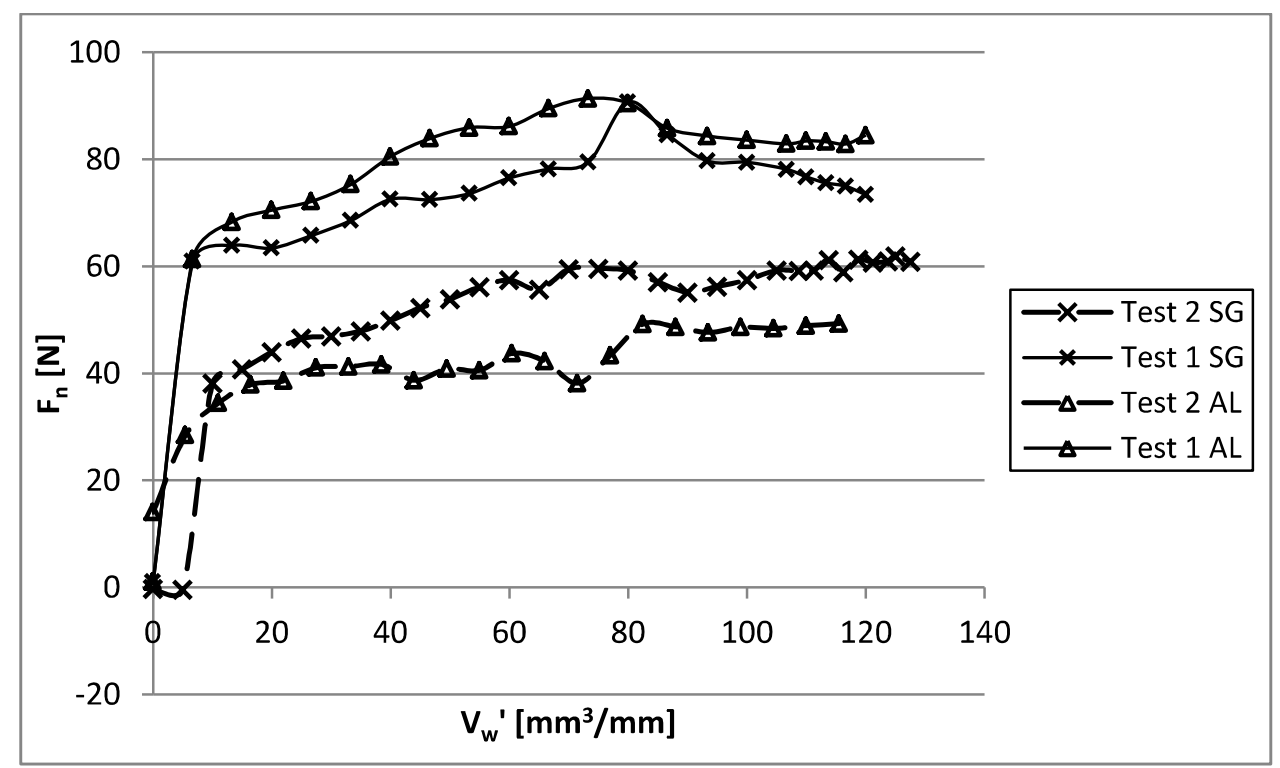

Figure 4. Normal forces comparison between Test $1\left(h_{e q}=7 \mathrm{~nm}\right)$ and Test $2\left(h_{e q}=18 \mathrm{~nm}\right)$. Dry grinding. 


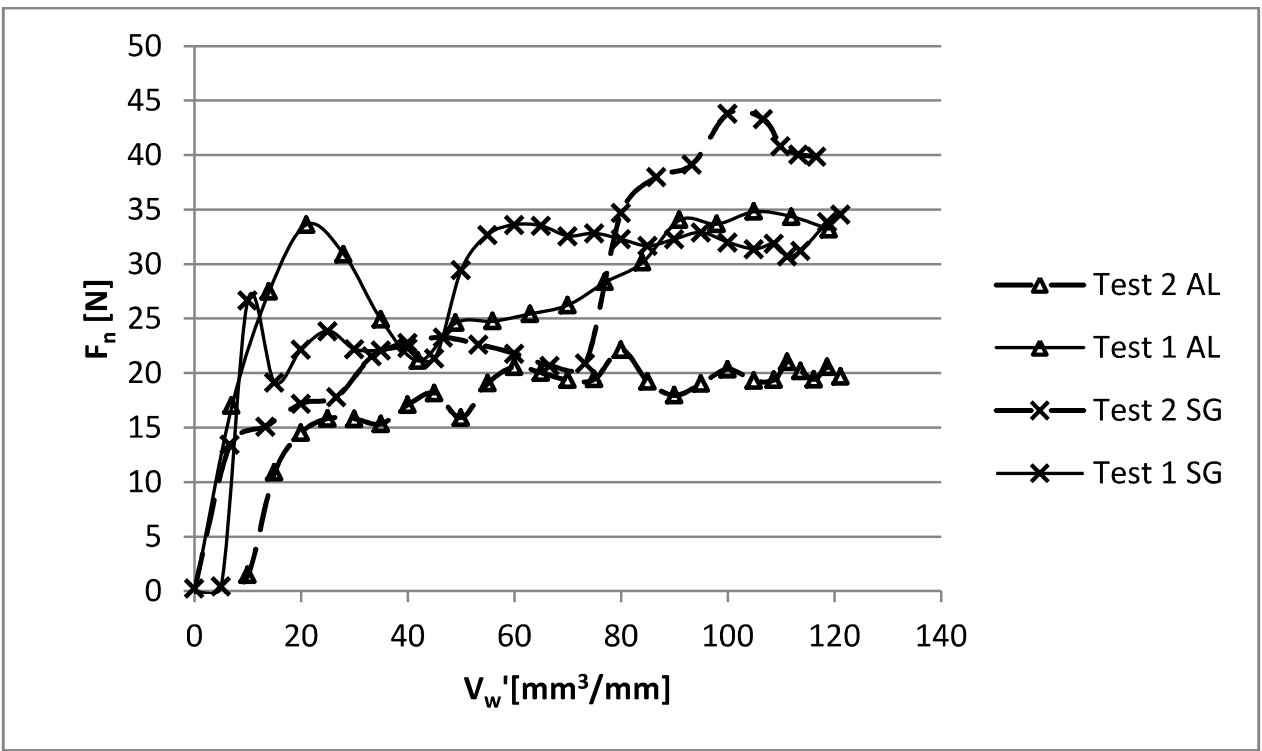

Figure 5. Normal forces comparison between Test $1\left(h_{e q}=7 \mathrm{~nm}\right)$ and Test $2\left(h_{e q}=18 \mathrm{~nm}\right)$. MCG.

The situation when MCG is applied is different. In Figure 5 it can be seen that in MCG grinding unlike Dry grinding normal forces profiles are quite similar and fluctuate between 20 and $45 \mathrm{~N}$ for both test conditions and grinding wheels. These results imply that the lubricant effect of the MCG favours the penetration of the grit in the material, in such a way that even at the low depths of cut of Test 1 the grits are able to remove the material by shearing it. This would be sound with the reduced $e_{c}$ consumption shown in Section 3.1, since shearing is a more efficient material removing mechanism.

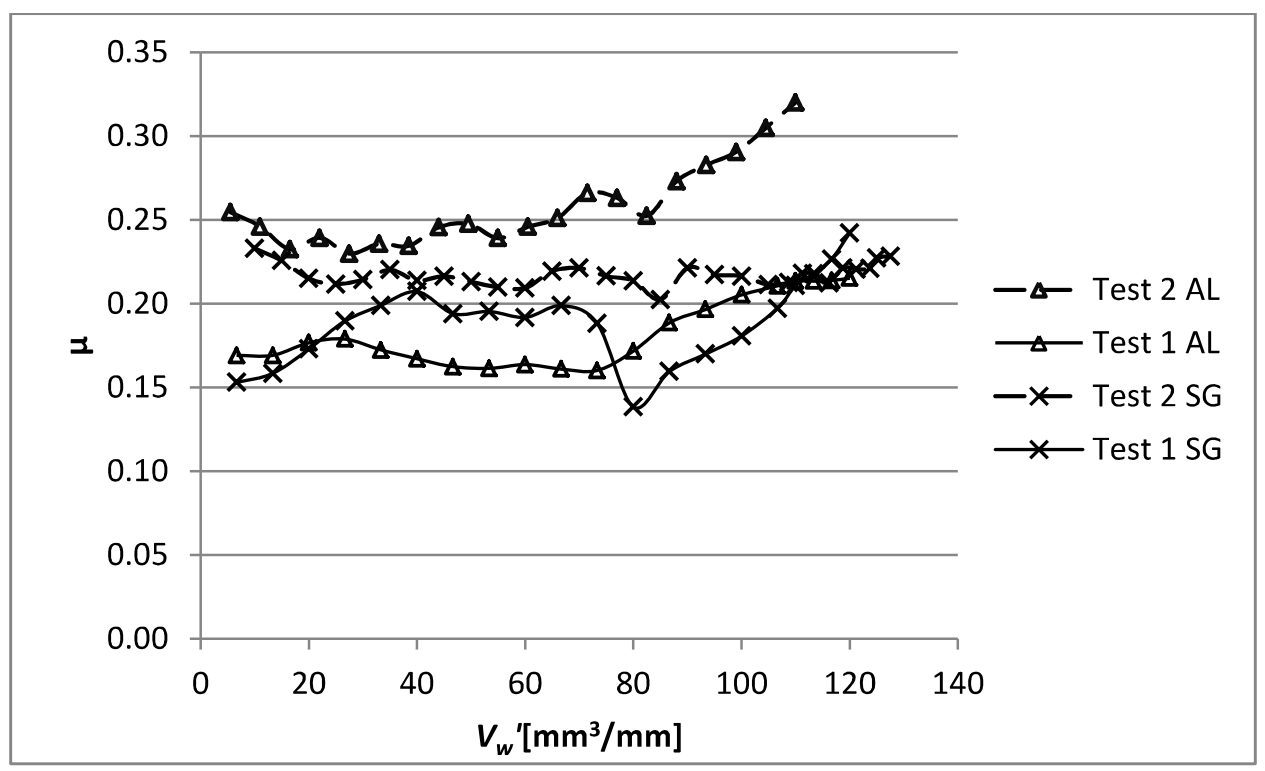

Figure 6. Friction index comparison between Test $1\left(h_{e q}=7 \mathrm{~nm}\right)$ and Test $2\left(h_{e q}=18 \mathrm{~nm}\right)$. Dry Grinding 
The results of friction index shown in Figure 6 (Dry) and Figure 7 (MCG) confirm these assumptions. In dry conditions (Figure 6), higher values can be overall noticed for the tests with $h_{e q}=18 \mathrm{~nm}$ (between 0.25 and 0.30 ) compared to friction index of the tests with $h_{e q}=7 \mathrm{~nm}$ (around 0.20 ).

Regarding the friction index with the MCG technique (Figure 7), higher values are observed compared to dry grinding, for both tested conditions: around 0.3 for $h_{e q}=7 \mathrm{~nm}$ (Test 1) and, between 0.4 and 0.5 for $h_{e q}=18 \mathrm{~nm}$ (Test 2). In [23] it was stated that typical values of abrasive machining range between 0.2 and 0.7 . Lower values correspond to abrasive grains rubbing against the surface and very little penetration, and higher values to sharp abrasive grains that effectively cut the material thanks to a deeper penetration. According to this, the high values of $\mu$ found in MCG grinding confirm that in both, Test 1 and Test 2, the material is being removed by shearing, while in Dry grinding shearing was only achieved with a higher $h_{e q}$ (Test 2).

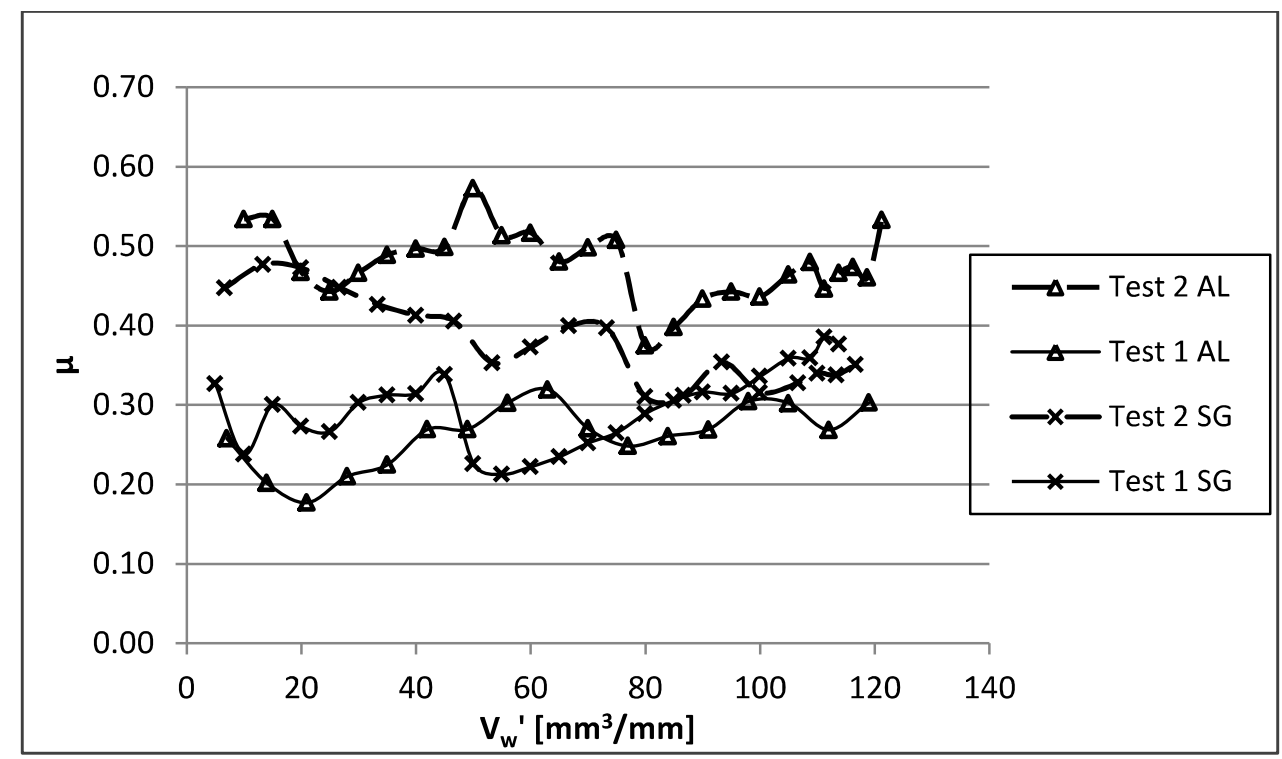

Figure 7. Friction index comparison between Test $1\left(h_{e q}=7 \mathrm{~nm}\right)$ and Test $2\left(h_{e q}=18 \mathrm{~nm}\right)$. MCG Grinding

At the sight of the results of forces and friction index it can be said that the effective lubrication provided by the MCG technique reduces the onset chip thickness below which rubbing takes over to very low values of $h_{\text {eq }}$. Cutting efficiency is increased and, consequently, energy consumption, process forces and abrasive attritious wear are reduced. The effect of lubrication in the transition between shearing and ploughing mechanisms was already investigated by [24] who considered the effect of the shear strength of the lubricating film, and lately by [25] where interfacial friction was included as one of the factors affecting the transition. In fact, the setting of a value for this transition is of maximum interest in the studies devoted to power and force modelling and prediction for grinding, as it is stated in [26]. 


\subsection{Observations of worn surfaces}

Optical and SEM observations are conducted on each sample to identify the tribological and wear mechanisms

\subsubsection{Optical Microscope Observations. Wear flat areas assessment}

Optical microscope observations have been used for identifying the percentage of wear flats areas arisen as a consequence of attritious wear. Light normally directed to the worn surface is reflected by the wear flats creating white areas easily recognizable as it is shown in Figure 8. The image shows clearly the different areas of light reflection. The obtained images are then treated using a methodology based on that described in [27]. Then, an image recognition routine allows estimating the percentage of area occupied by the wear flats. Taking into account the stochastic nature of grinding wheel topography, the analysis of wear flat areas has been done on two samples per test of about $25 \mathrm{~mm}$ long extracted from different locations of the wheel.
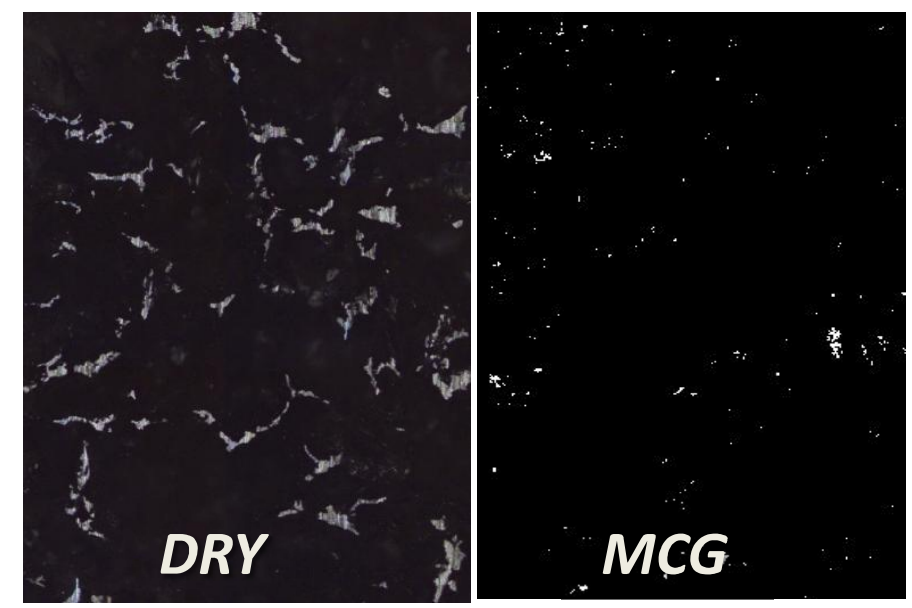

Figure 8. Optical Microscope image of Test 1 Dry grinding using AL.

Table 2 gathers the mean values of wear flats measured for MCG and Dry grinding for the different wheels and conditions tested:

\begin{tabular}{|c|r|r|r|r|}
\hline \multirow{2}{*}{$\begin{array}{c}\text { \% Wear Flat } \\
\text { Areas }\end{array}$} & \multicolumn{2}{|c|}{ AL } & \multicolumn{2}{c|}{ SG } \\
\hline DRY & $3.30 \%$ & $0.93 \%$ & $2.04 \%$ & $1.41 \%$ \\
\hline MCG & $0.24 \%$ & $0.16 \%$ & $1.12 \%$ & $0.14 \%$ \\
\hline
\end{tabular}

Table 2. Mean value in of the percentage of wear flat areas on worn surfaces measured by optical microscope observations.

Results exposed in Table 2 show that the percentage of wear flat areas generated in Dry grinding is higher than that of MCG grinding for all tested conditions and wheel types. For example, with AL the mean wear flat area of Dry grinding is $3.30 \%$ and for MCG grinding is reduced to $0.24 \%$. This difference persist also with SG, although the difference is smaller: $2.04 \%$ for Dry grinding compared to $1.12 \%$ 
of MCG grinding. The protection of the abrasive grits achieved by the MCG system reduces wear in such a way that negligible differences are found between AL and SG grinding wheels. Whatsoever, MCG systems allows reducing tool costs without penalizing wear performance. This reduced wear is coherent with energy consumption and process forces previously analyzed.

The generation of wear flats is a consequence of attritious wear and is promoted by elevated punctual temperature that takes place in the contact between the grit and the workpiece. Therefore, the reduced percentage of wear flat areas found in MCG grinding suggests a lower local temperature. The local temperature at the grit-workpiece contact has not been measured in these tests due to its complexity. Nevertheless, an indirect mean for estimating contact temperature is used: the geometry of the grinding chips observed by SEM give information on the reached temperature range (as it is addressed in Section 3.3.2).

Regarding the effect of cutting parameters the attritious wear is reduced with the increase of the depth of cut in all cases. In Dry grinding when $h_{e q}$ is increased from 7 to $18 \mathrm{~nm}$, wear flats are reduced from $3.30 \%$ to $0.93 \%$ with AL and from $2.04 \%$ to $1.41 \%$ with SG.

Finally it has to be mentioned that in MCG grinding there is an increase of $e_{c}$ along the test that is similar to that of Dry grinding. This increase in $e_{c}$ consumption is due to the loss of cutting capacity of the wheel. In Dry grinding the elevated values of wear flat areas are responsible for this increase in $e_{c}$ consumption. However, it has been shown (Table 2) that the percentage of wear flat areas in MCG grinding is very small. Consequently, the increase of $e_{c}$ energy in MCG grinding along the test cannot be attributed to attritious wear but to loading of the wheel as it is shown in Section 3.3.2.

\subsubsection{SEM Observations}

SEM observations of the wheel worn surface give additional information on the frictional and wear effects, the formation of the debris, and the material transfer. Moreover EDX analyses are performed to identify the areas of steel transfer on the wheels. Three elements are searched: iron (red) from the steel workpiece, aluminium (green) from the $\mathrm{Al}_{2} \mathrm{O}_{3}$ abrasive grits, and silica (yellow) from $\mathrm{SiO}_{2}$ used to link the grits..

Analysis of the images shown clear differences between the different tested conditions, and serve to confirm the aspects pointed out during the analysis of results along Section 3.

Firstly, low magnification images are shown in order to have a global view of the surface. Figure 9 shows 50X images of AL samples used under heq=7nm: dry grinding in the left, and MCG grinding in the right image. 

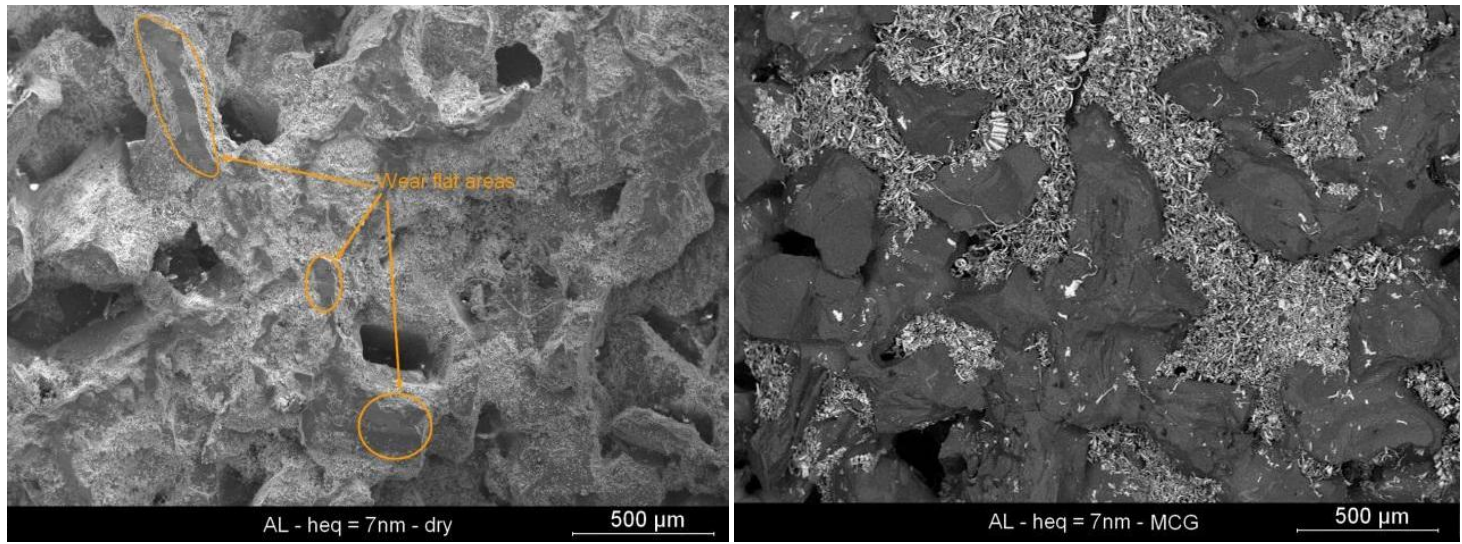

Figure 9.50X images of the surface of AL after Test 1: Left, Dry grinding, Right, MCG grinding.

In the left image of Figure 9 (Dry grinding) it is possible to identify wear flat areas arisen as a consequence of attritious wear. These wear flats areas rare not visible on the right image (MCG grinding). This means that the protective action of the MCG allows the abrasive grits remaining sharp. Regarding the EDX analyses of these two surfaces (Figure 10), it can be observed a filling of the porosities by steel debris. In Dry grinding, the steel debris seems to be smaller and form a condensed volume. By contrast, in MCG grinding, they have an acicular geometry. These chips correspond to the loading of the wheel. The photographs confirm, thus, that this effect is responsible for the increase of $e_{c}$ in the MCG technology above mentioned.
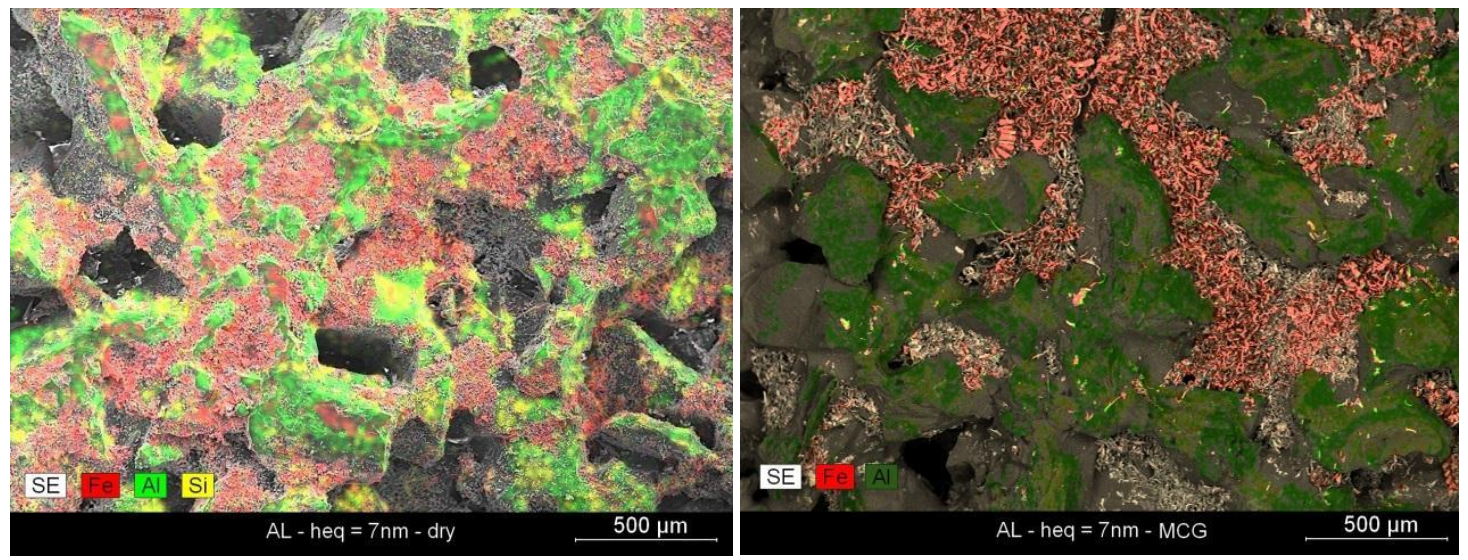

Figure 10. EDX analysis for AL with $h_{e q}=7 \mathrm{~nm}$ : Left, Dry grinding; Right, MCG grinding

Figure 11 presents the surface of the SG wheel after Dry grinding at $h_{e q}=7 \mathrm{~nm}$ observed at two different magnifications: 50x left, and 350x right. At low magnification ( $\mathrm{x} 50$ ), it can be seen that the steel chips fill the porosity of the wheel as it was pointed out in AL wheel (Figure 9). When the magnification is increased (x350), it can be observed that chips have a globular shape and they seem to be adhered to each other and to the abrasive grits. These characteristics correspond to the melting chip type described in [28] and are an indirect sign of very high local contact temperatures. Looking at the wear flat areas, a steel flat layer can also be found over the grits. 

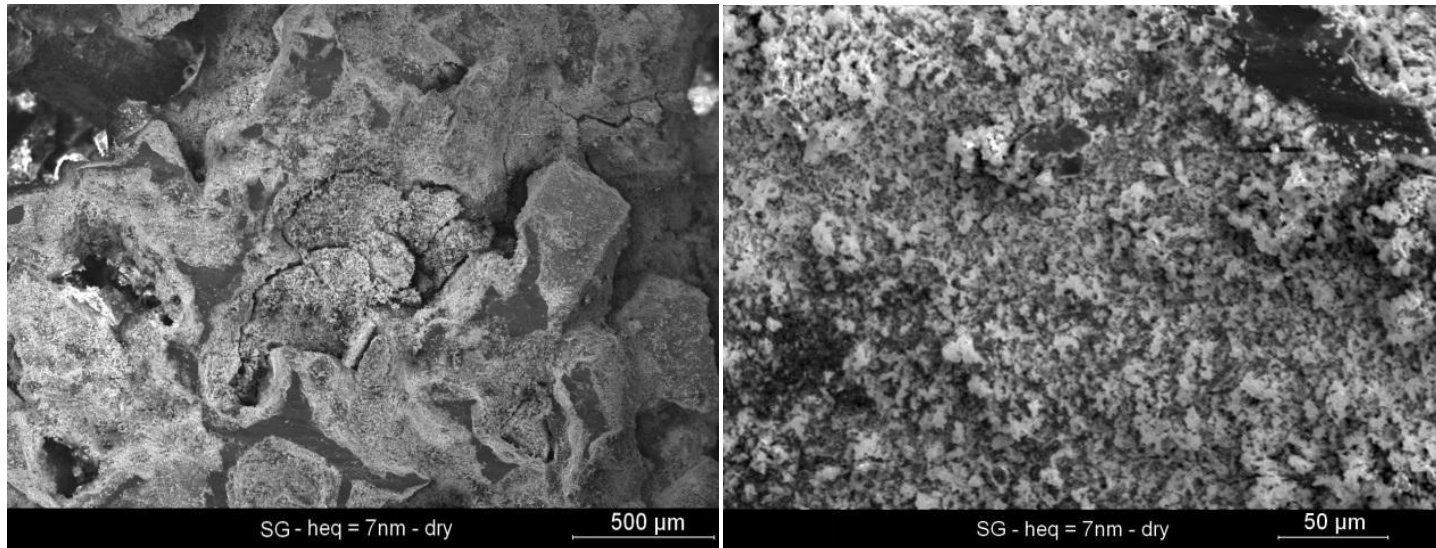

Figure 11. Globular steel debris in dry conditions for SG with $h_{e q}=7 \mathrm{~nm}$ : Left, 50x; Right, 350x

The Figure 12 present the adhered steel layer observed at higher magnification for $\mathrm{AL}-h_{e q}=7 \mathrm{~nm}$ (left), and $\mathrm{SG}-h_{e q}=18 \mathrm{~nm}$ (right). The debris are adhered on the grit surfaces and have formed continuous areas of contact. The high temperature and the local contact pressure must favour the adhesion and the spread along the sliding path. The steel layer changes the nature of the contact and is probably responsible of the loss of cut efficiency.
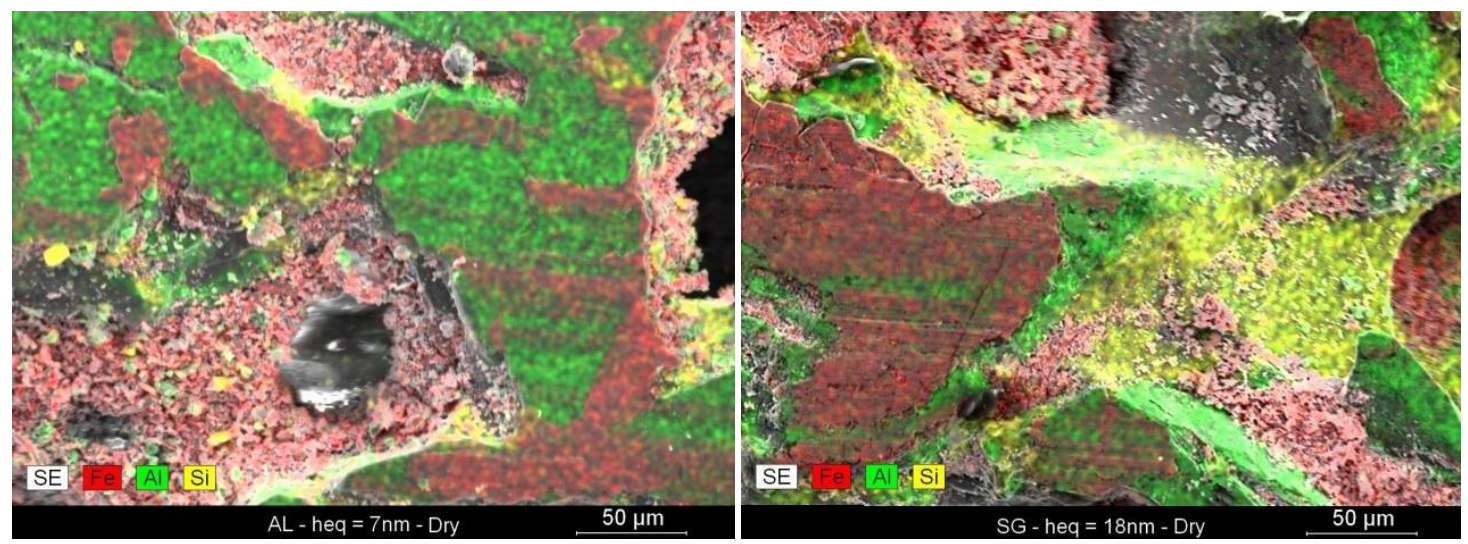

Figure 12. Steel layer formation under dry conditions: Left, AL $h_{e q}=7 \mathrm{~nm}$; Right, SG $h_{e q}=18 \mathrm{~nm}$

Figure 13 shows the workpiece debris in the AL wheel for $h_{e q}=7 \mathrm{~nm}$ in MCG grinding. Observing higher magnifications for MCG conditions reveal clearly an acicular geometry of the steel chips. This kind of chips is formed when shearing is predominant according to [28]. In MCG condition the chips are not attached to the grits and does not form a porous medium compared to dry condition. This indicates that contact temperature must be lower and that the chips have not reached the melting temperature. Besides no steel layer is observed on the grit surface. The MCG allows avoiding adhesive phenomena. This may explain the lower $e_{c}$ consumption and the reduced wear of the abrasive. 


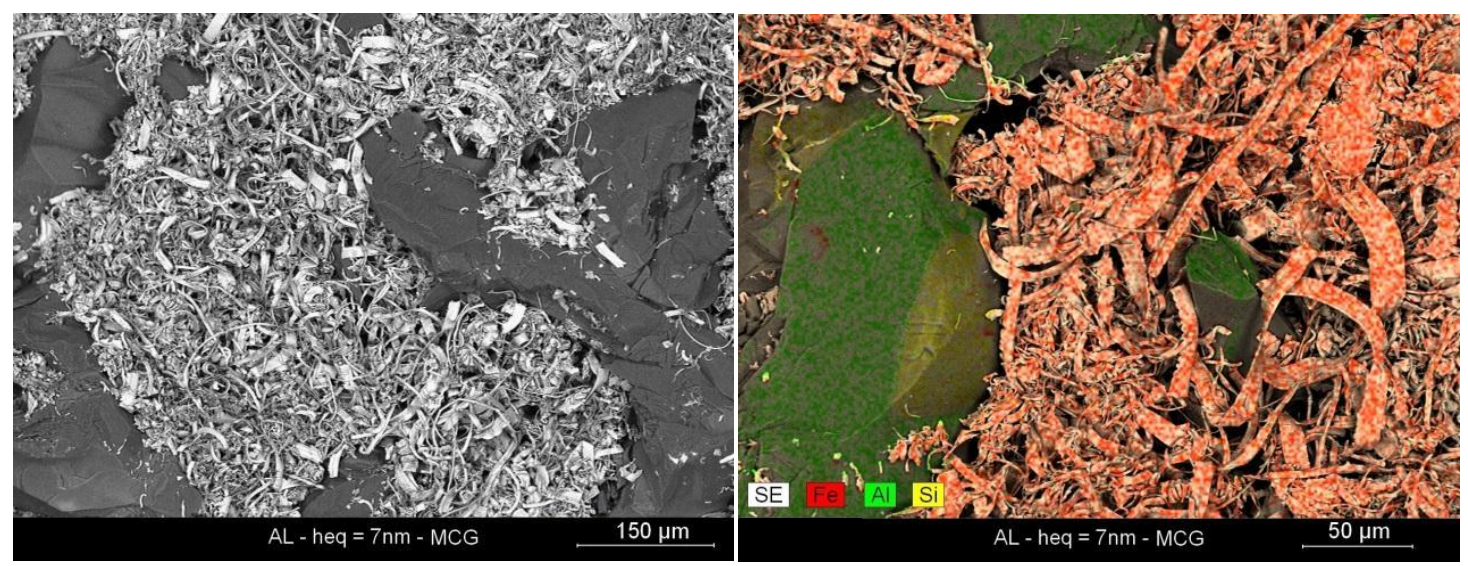

Figure 13. Acicular steel debris in MCG conditions for AL with $h_{e q}=7 \mathrm{~nm}$ : Left, 150x Right-350x
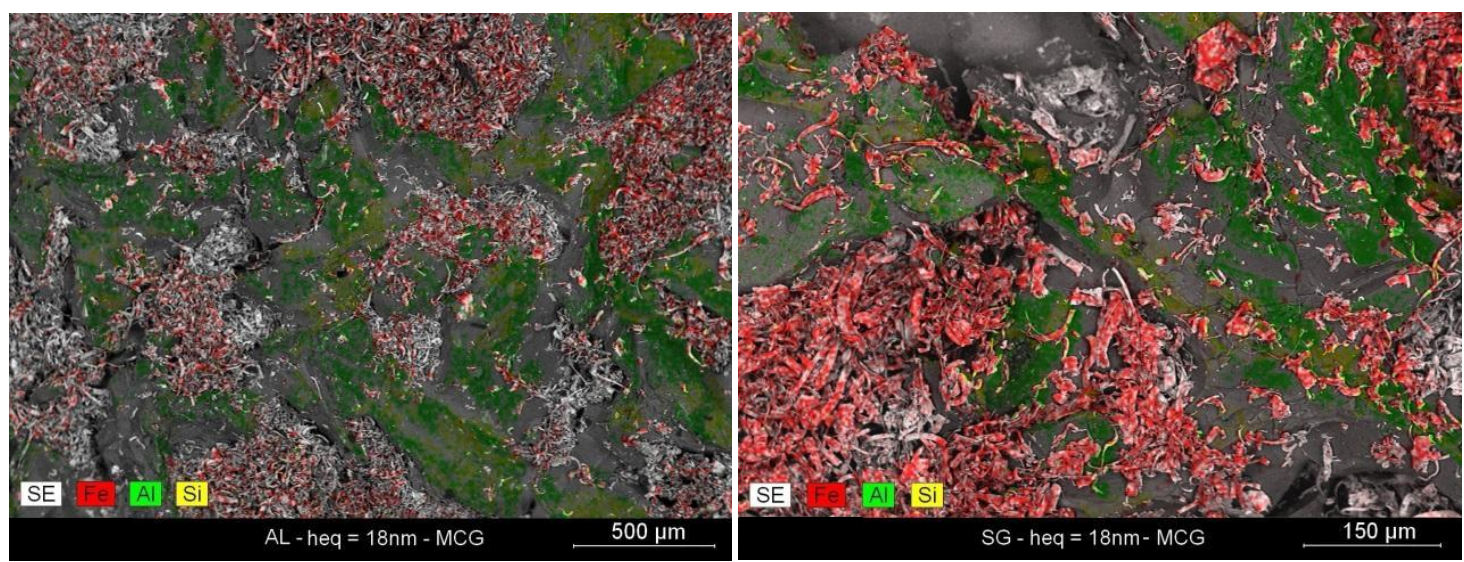

Figure 14. Steel wear debris in MCG conditions for $h_{e q}=18 \mathrm{~nm}$ : Left, AL; B, SG

Finally, Figure 14 shows observations made over AL and SG material for an equivalent chip thickness of $18 \mathrm{~nm}$ with the MCG technique. The shape of the debris is similar to those found for $h_{e q}=7 \mathrm{~nm}$. No steel layer is neither observed over the grit surface.

\section{CONCLUSIONS}

In this paper the role of the frozen lubricant used by the MCG technology is studied regarding the energy consumption and the tribological behaviour of the grinding wheel. From the work carried out and presented in this document the following conclusions can be drawn:

- The MCG technology has shown a remarkable capacity for improving efficiency of the grinding process. The improvement of the cutting efficiency is remarkable for the lowest chip thickness: $290 \mathrm{~J} / \mathrm{mm}^{3}$ for MCG grinding compared to $150 \mathrm{~J} / \mathrm{mm}^{3}$ at the beginning of the Dry grinding test with $h_{e q}=$ $7 \mathrm{~nm}$. This lowering is due to the improved lubrication provided by the MCG technique. 
- In dry grinding normal forces decrease when the depth of cut is increased from $90 \mathrm{~N}$ to $50 \mathrm{~N}$, because the main cutting mechanisms passes from ploughing to shearing. However, in MCG when the depth of cut is increased normal forces only decrease from $45 \mathrm{~N}$ to $35 \mathrm{~N}$. This different behaviour between MCG and Dry grinding, indicates that the improved lubrication provided by MCG favours the penetration of the grit on workpiece material reducing, this way, the limit between shearing and ploughing to very low values of $h_{e q}$. This is confirmed by the high values of friction index found in MCG grinding (0.4-0.5) compared to those of Dry grinding (0.2-0.3).

- In Dry grinding, larger amount of wear flat areas has been highlighted by optical observations compared to tests with MCG. SEM observations combined with EDX analyses showed two kind of steel layer. On the one hand, a homogeneous steel layer adhered on the grit surface. The combination of high working temperature and high pressure favour this kind of transfer. The metal is spread out in the sliding direction. On the other hand, wear debris accumulated in the porosities forming steel porous volumes. They suggest that local contact temperature must reach the melting point but the pressure is probably lower, which would agree with the fact that these steel volumes are less compacted.

- With MCG technology, the lubricant contributes to reduce the local pressure and the temperature elevation. This explains that steel chips have not reached the melting temperature. No adhered steel layer is observable on the $\mathrm{AL}_{2} \mathrm{O}_{3}$ grits. During friction, the acicular steel debris may not support a high pressure because they look like free matter. In addition, the wear flat areas identified by optical microscope are for ten times smaller compared to dry conditions as a consequence of the more efficient material removing mechanism promoted by the improved lubrication: shearing.

The study presented has shown the role of MCG technology in grinding of hardened steels at low $h_{e q}$ values (finishing and semi-finishing conditions). Further work will be developed for understanding the effect of MCG in more aggressive conditions, typical of roughing grinding operations.

\section{ACKNOWLEDGEMENTS}

The present research work has also been supported by the International Campus on Safety and Intermodality in Transportation, the Nord Pas-de-Calais Region, the European Community, the Regional Delegation for Research and Technology, the French Ministry of Higher Education and Research, the Carnot Arts Institute. 


\section{REFERENCES}

[1] Hahn RS (1966) On the Mechanics of the Grinding Process under Plunge Cut Conditions. Trans ASME, J Eng Ind 72-80.

[2] Brinksmeier, E, Heinzel C, Wittmann (1999) M Friction Cooling and Lubrication in Grinding. Ann CIRP 48- 2.

[3] Yoshikawa H, Sata T (1963) Study on wear of grinding wheels. J Eng Ind Trans ASME 85.

[4] Malkin S, Cook NH (1971) The wear of grinding wheels. J Manuf Sci Eng 93(4): 1120-1133.

[5] Erickson LC, Blomberg A, Hogmark S, Bratthall J (1993) Tribological characterization of alumina and silicon carbide under lubricated sliding. Tribol Int. 2: 83-92.

[6] Zeng P, Rainforth WM, Inkson BJ, Stewart TD (2012) Transmission electron microscopy analysis of worn alumina hip replacement. Actar Materialia 60: 2061-2072.

[7] Jackson MJ, Davim JP, Machining with Abrasives. Springer Science Business Media, LLC, 2011; New York.

[8] Irani RA, Bauer RJ, Warkentin A (2005) A review of cutting fluid application in the grinding process. Int J Mach Tools Manuf 45(15): 1696-1705.

[9] Li C, Zhang X, Zhang Q, Wang S, Zhang D, Jia D, Zhang Y (2014) Modeling and Simulation of useful fluid flow rate in grinding. Int J Adv Manuf Technol 75:1587-1604.

[10] Coes Jr L, (1971) “Abrasives”. Spriger-Verlag, New York, 1971;Chapter 14.

[11] Malkin S, Guo C (2008) Grinding technology-theory and applications of machining with abrasives. Industrial Press, New York.

[12] Winter M, Thiede S, Herrmann C (2014) Influence of the cutting fluid on process energy demand and surface roughness in grinding - a technological, environmental and economic examination. Int J Adv Manuf Technol DOI 10.1007/s00170-014-6557-1.

[13] Ben Fredj N, Sidhom H, Braham C (2006) Ground surface improvement of the austenitic stainless steel AISI 304 using cryogenic cooling. Surf and Coat Tech 16-17: 4846-4860.

[14] Nguyen T, Zhang L (2003) An assessment of the applicability of cold air and oil mist in surface grinding. J Mater Process Tech 140(1-3): 224-230.

[15] Barczak LM, Batako DL, Morgan MN (2010) A study of plane surface grinding under minimum quantity lubrication (MQL) conditions. Int J Mach Tools Manuf 50: 977-985.

[16] Davim JP (2008) Machining: fundamentals and recent advances. Volume 10. XIV, 361 p. 222 illus. Springer.

[17] Zhang D, Li C, Zhang Y, Jia D, Zhang X (2015) Experimental research on the energy ratio coefficient and specific grinding energy in nanoparticle jet MQL grinding. Int J Adv Manuf Technol DOI 10.1007/s00170-014-6722-6. 
[18] Sanchez, J, Pombo I, Alberdi R, Izquierdo B, Ortega N, Plaza S, MartinezToledano J (2010) Machining evaluation of a hybrid MQL-CO2 grinding technology. J Clean Prod 18(18): 1840-1849.

[19] Garcia E, Pombo I, Sanchez JA, Ortega N, Izquierdo B, Plaza S, Marquinez J.I, Heinzel C, Mourek D (2013) Reduction of oil and gas consumption in grinding technology using pour-point lubricants J Clean Prod 51: 99-108.

[20] Garcia E, Sanchez JA, Meresse D, Pombo I, Dubar L (2014) Complementary Tribometers for the Analysis of Contact Phenomena in Grinding. J Mater Process Tech 214-9: 1787-1797.

[21] Marinescu ID, Rowe WB, Dimitrov B, Inasaki I (2004) Tribology of Abrasive Machining Processes. William Andrew Publishing.

[22] Bange D, Wood B, Erickson D (2001) Abras Mag June/July 24-30.

[23] Marinescu I, Rowe B, Dimitrov B, Inasaki I (2004) Tribology of Abrasive Machining Processes. J. Manuf. Sci. Eng: 126; 859.

[24] Challen JM, Oxley PLB (1978) An explanation of the different regimes of friction and wear using asperity deformation models. Wear 53: 229-243.

[25] Xie Y, Williams JA (1996) The prediction of friction and wear when a soft surface slides against a harder rough surface, Wear 196: 21-34.

[26] Hecker RL. Liang SY . Wu XJ. Xia P. Wei Jin DG (2007) Grinding force and power modeling based on chip thickness analysis. Int J Adv Manuf Technol 33: 449-459 DOI 10.1007/s00170-006-0473-y.

[27] Oliveira JFG, Coelho RT, Neto CK (1999) Development of an optical scanner to study wear on the working surface of grinding wheels. Machin Sci Technol 3(2): 239-253.

[28] Tso PL (1995) An investigation of chip types in grinding. J. Mater Process. Tech. 53: 521-532. 


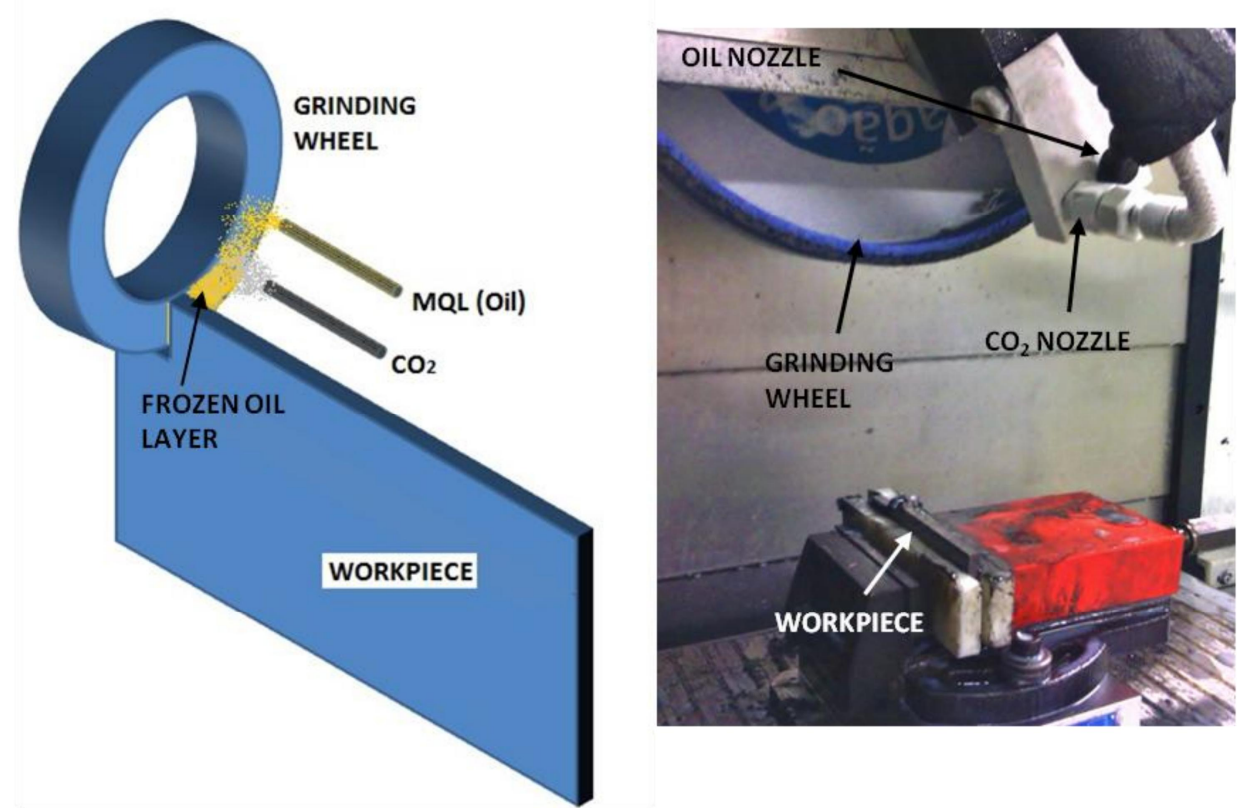

Figure 1. Test bench schema showing the different components and real layout. 


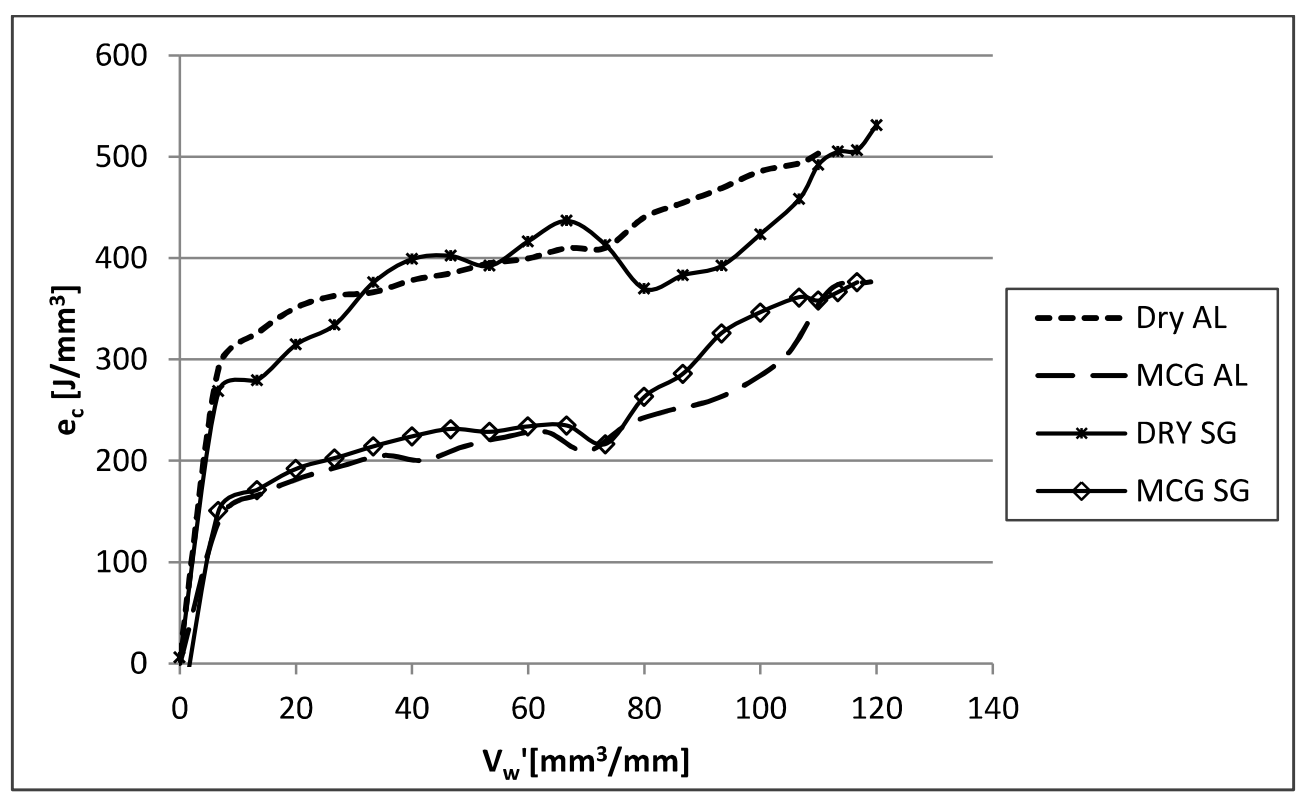

Figure 1. Comparison of $e_{c}$ consumption for MCG and Dry grinding in Test 1. $\mathrm{Q}^{\prime}=0.17 \mathrm{~mm}^{3} / \mathrm{mm} \cdot \mathrm{s}, h_{e q}=7 \mathrm{~nm}$ 


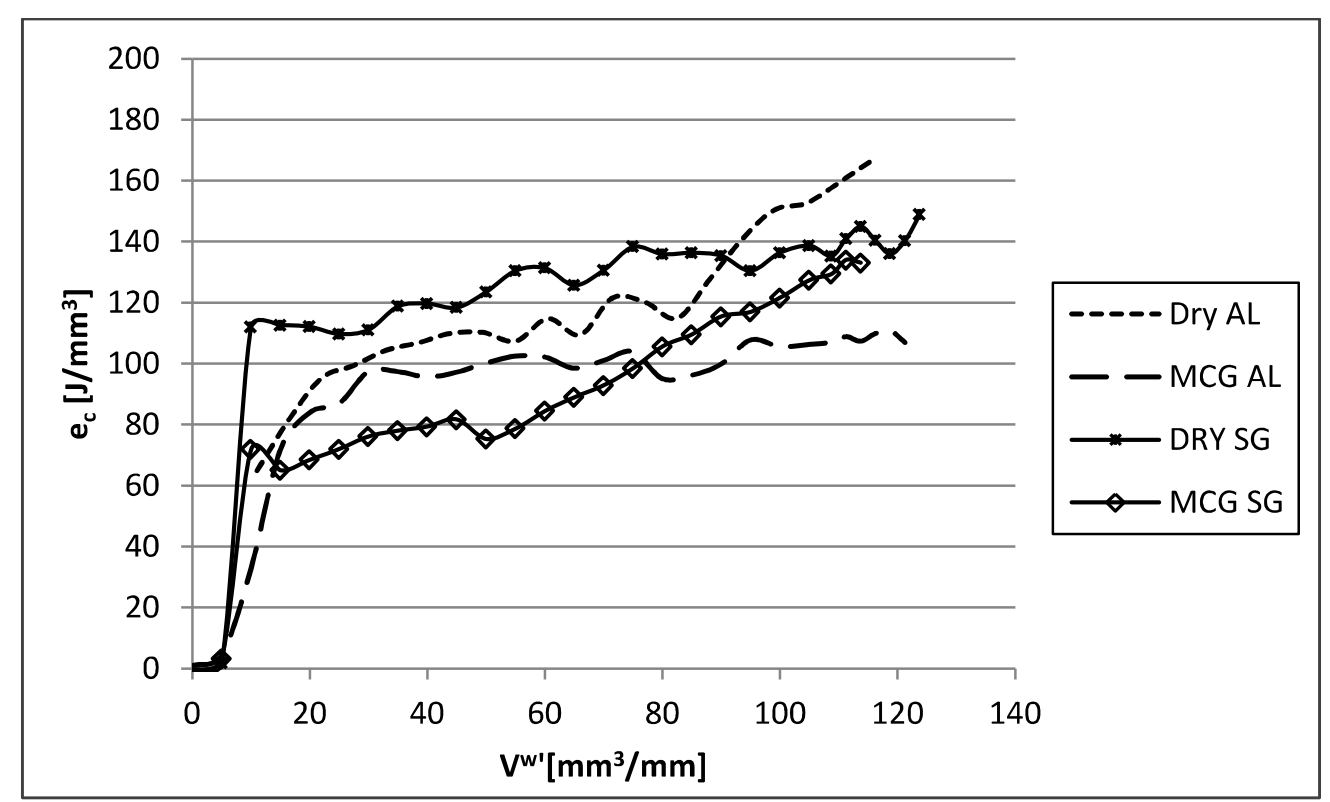

Figure 1 Comparison of $e_{c}$ consumption for MCG and Dry grinding in Test 2 conditions. Q'= $0.42 \mathrm{~mm}^{3} / \mathrm{mm} \cdot \mathrm{s}, h_{e q}=18 \mathrm{~nm}$ 


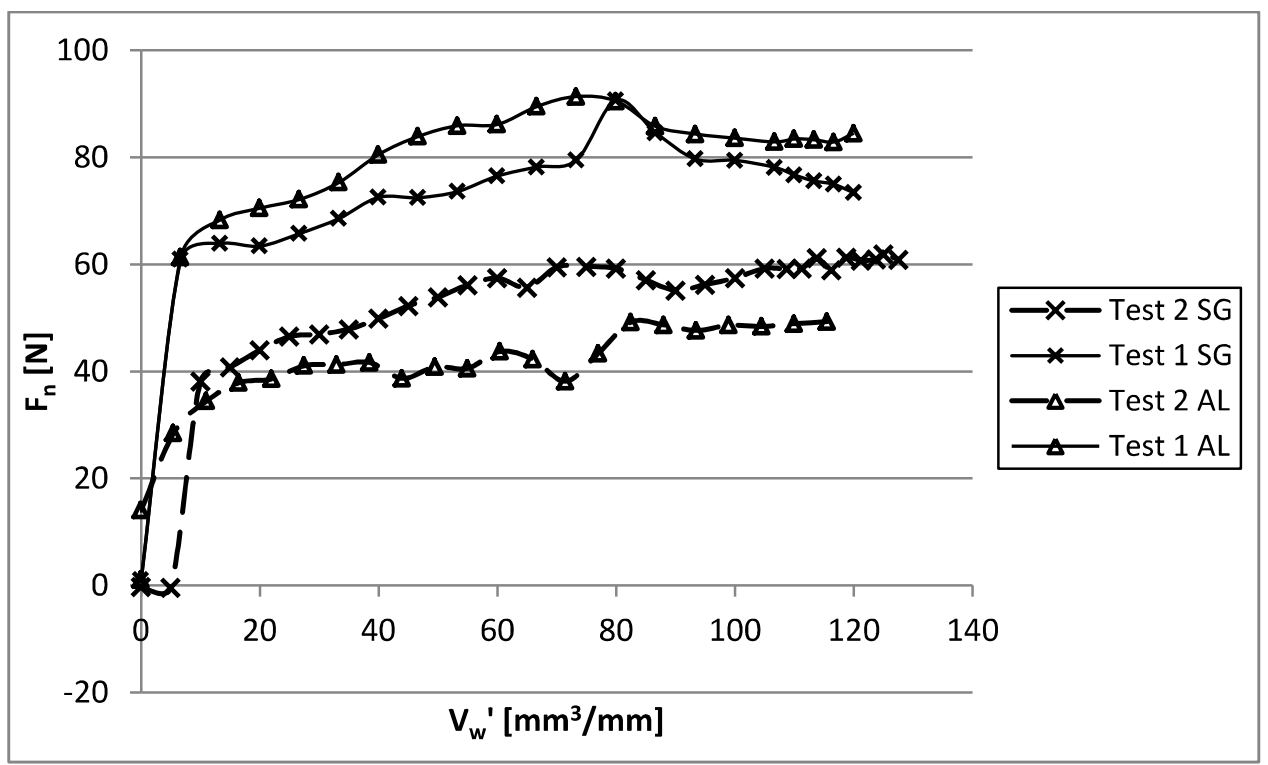

Figure 1. Normal forces comparison between Test $1\left(h_{e q}=7 \mathrm{~nm}\right)$ and Test $2\left(h_{e q}=18 \mathrm{~nm}\right)$. Dry grinding. 
Click here to download Figure: Figure 5.docx

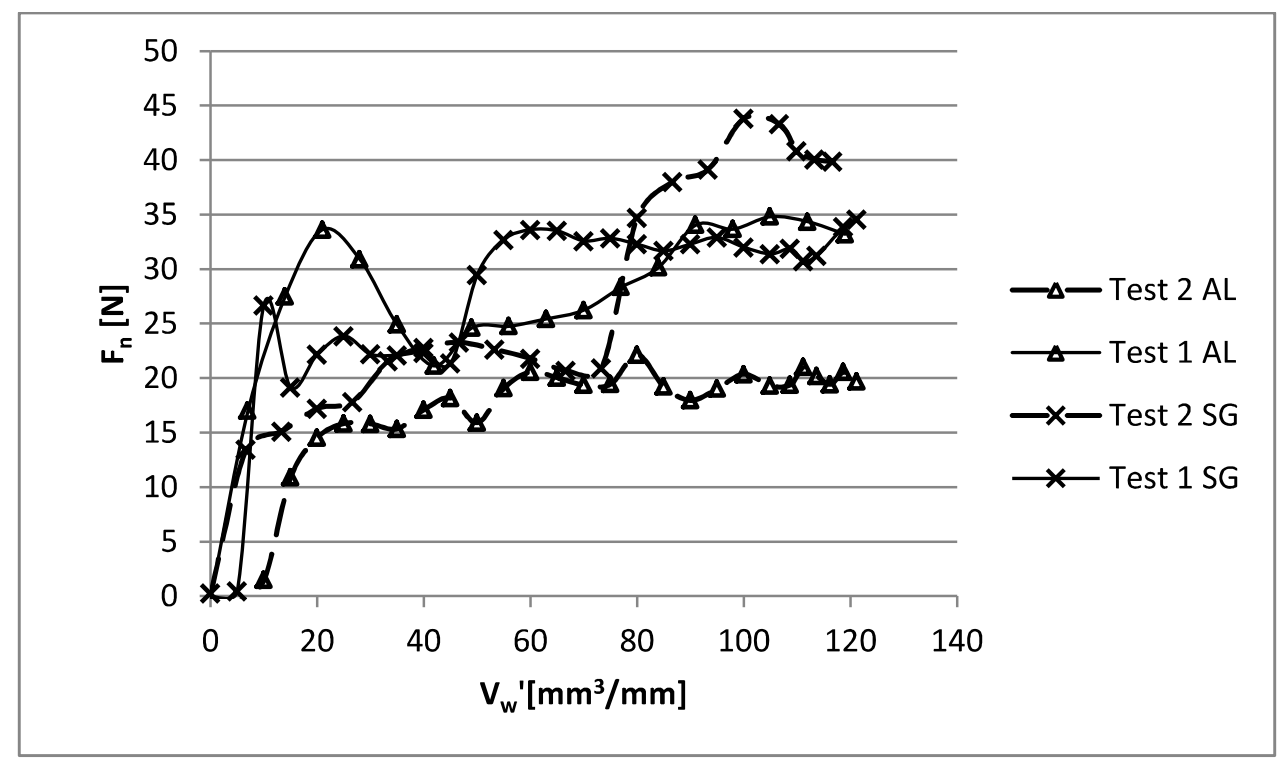

Figure 1. Normal forces comparison between Test $1\left(h_{e q}=7 \mathrm{~nm}\right)$ and Test $2\left(h_{e q}=18 \mathrm{~nm}\right)$. MCG. 


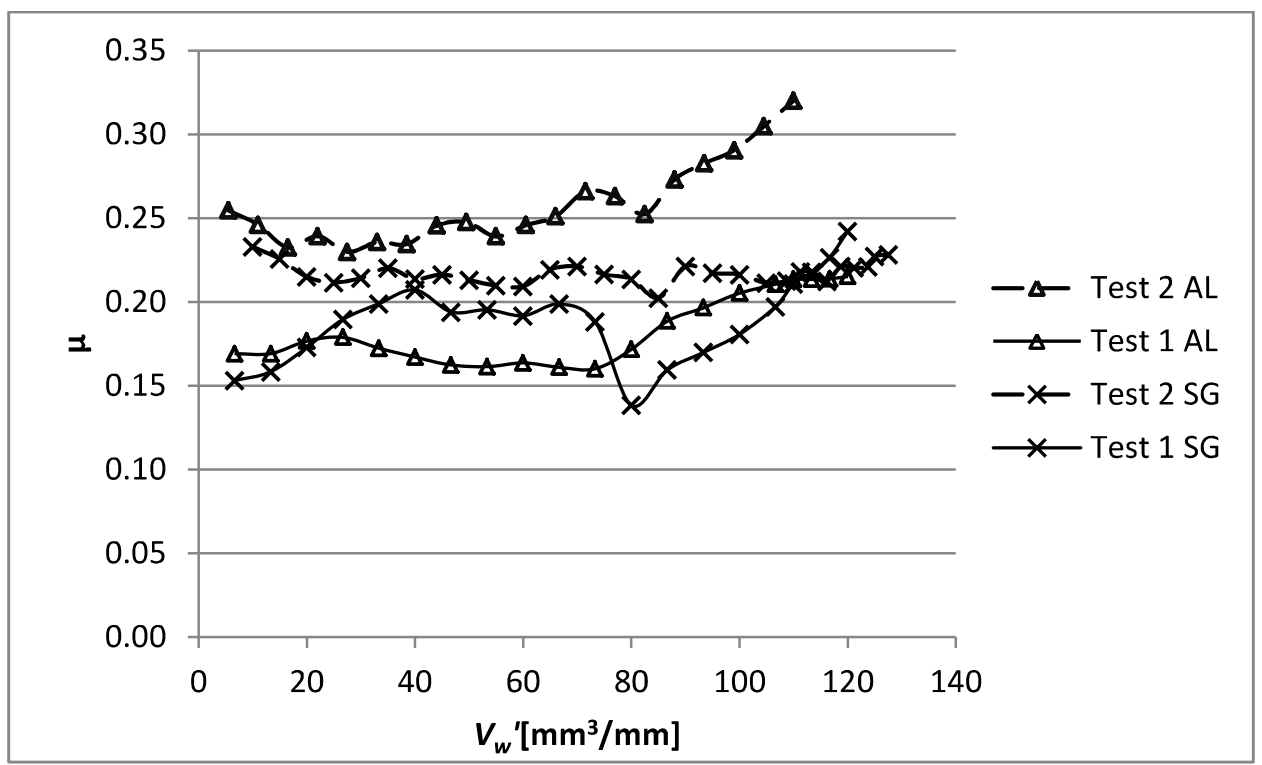

Figure 1. Friction index comparison between Test $1\left(h_{e q}=7 \mathrm{~nm}\right)$ and Test $2\left(h_{e q}=18 \mathrm{~nm}\right)$. Dry Grinding 


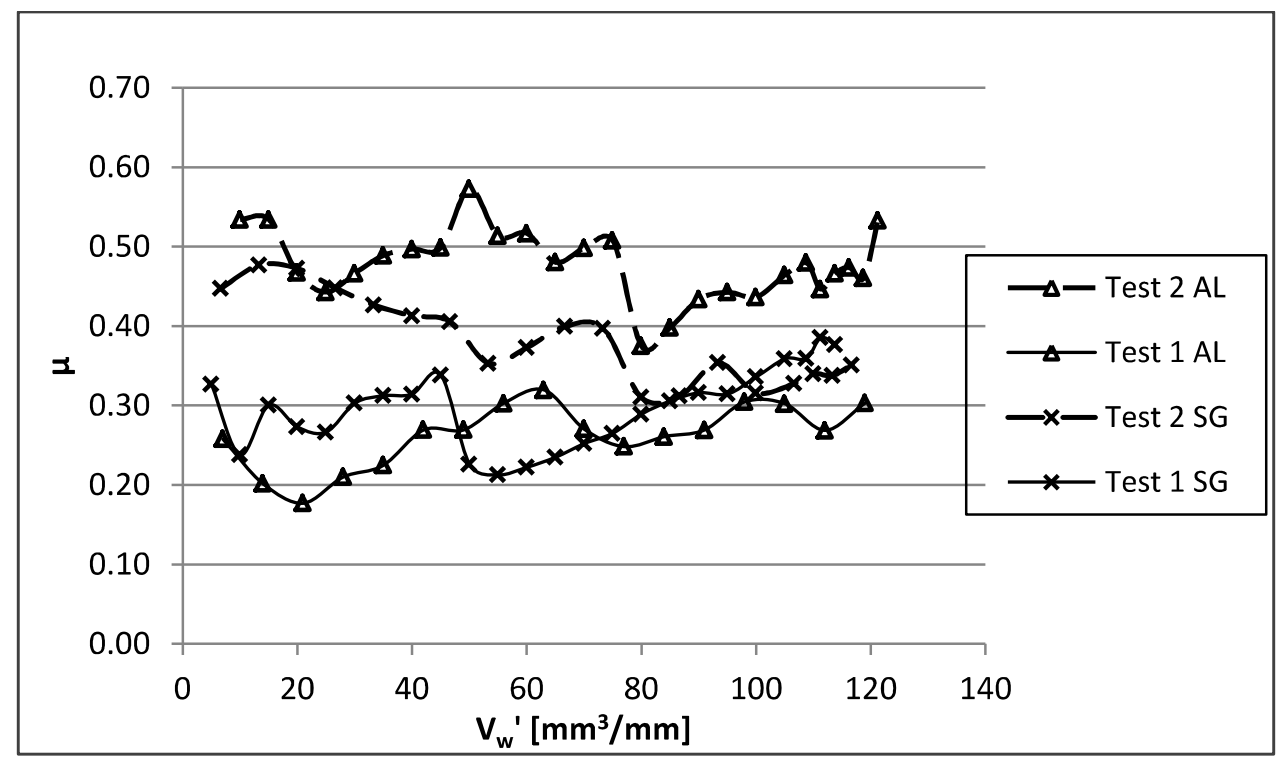

Figure 1. Friction index comparison between Test $1\left(h_{e q}=7 \mathrm{~nm}\right)$ and Test $2\left(h_{e q}=18 \mathrm{~nm}\right)$. MCG Grinding 
Click here to download Figure: Figure 8.docx

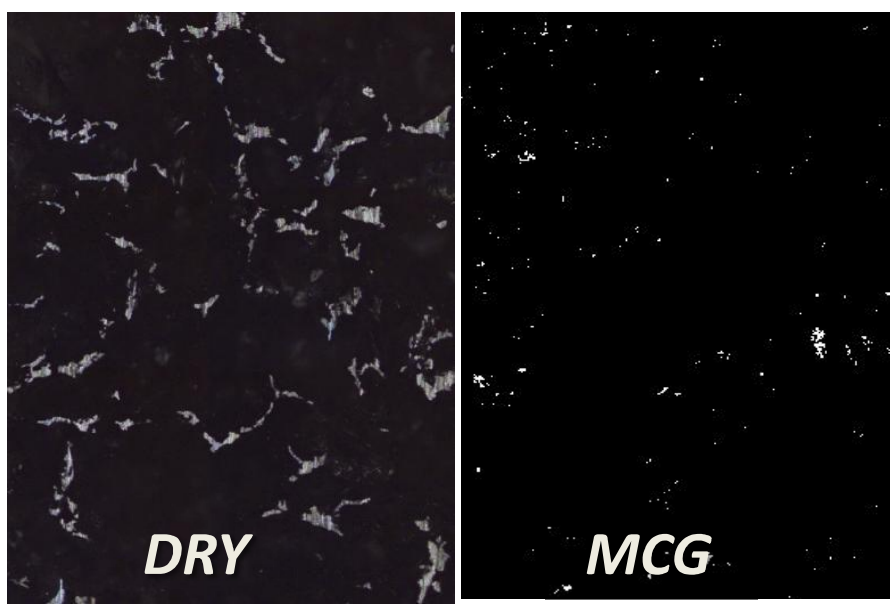

Figure 1. Optical Microscope image of Test 1 Dry grinding using AL. 


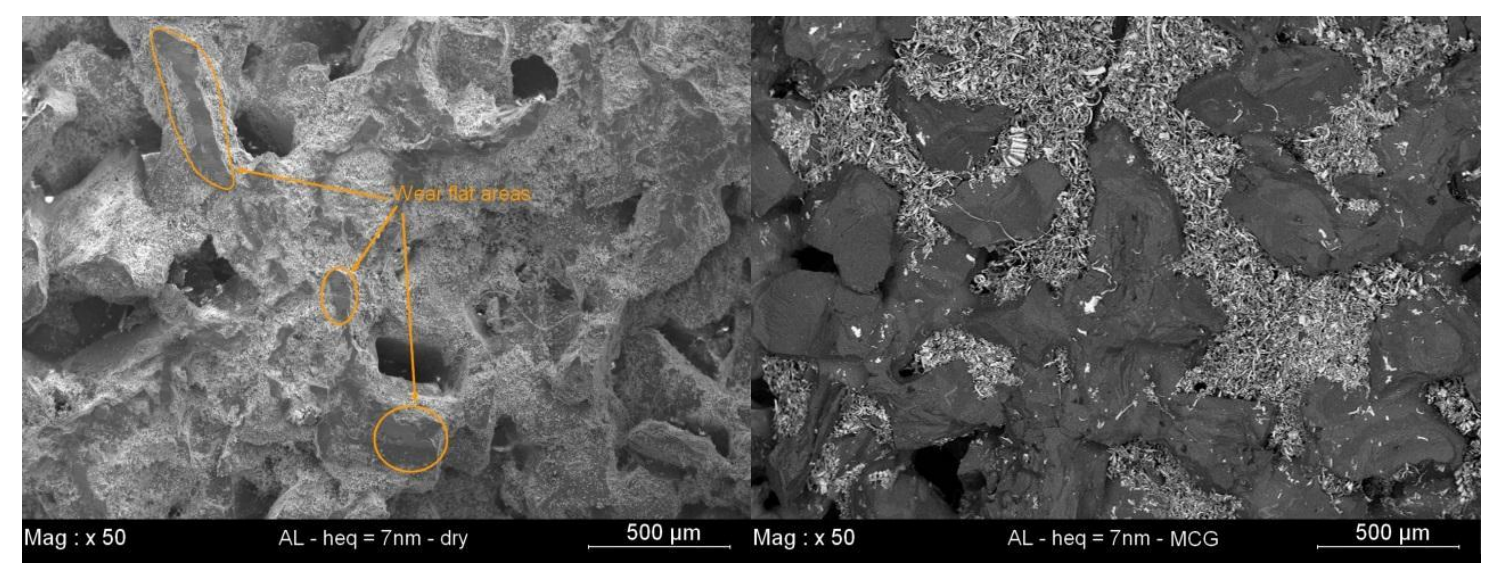

Figure 1. 50X images of the surface of AL after Test 1: Left, Dry grinding, Right, MCG grinding. 
Figure 10

Click here to download Figure: Figure 10.docx

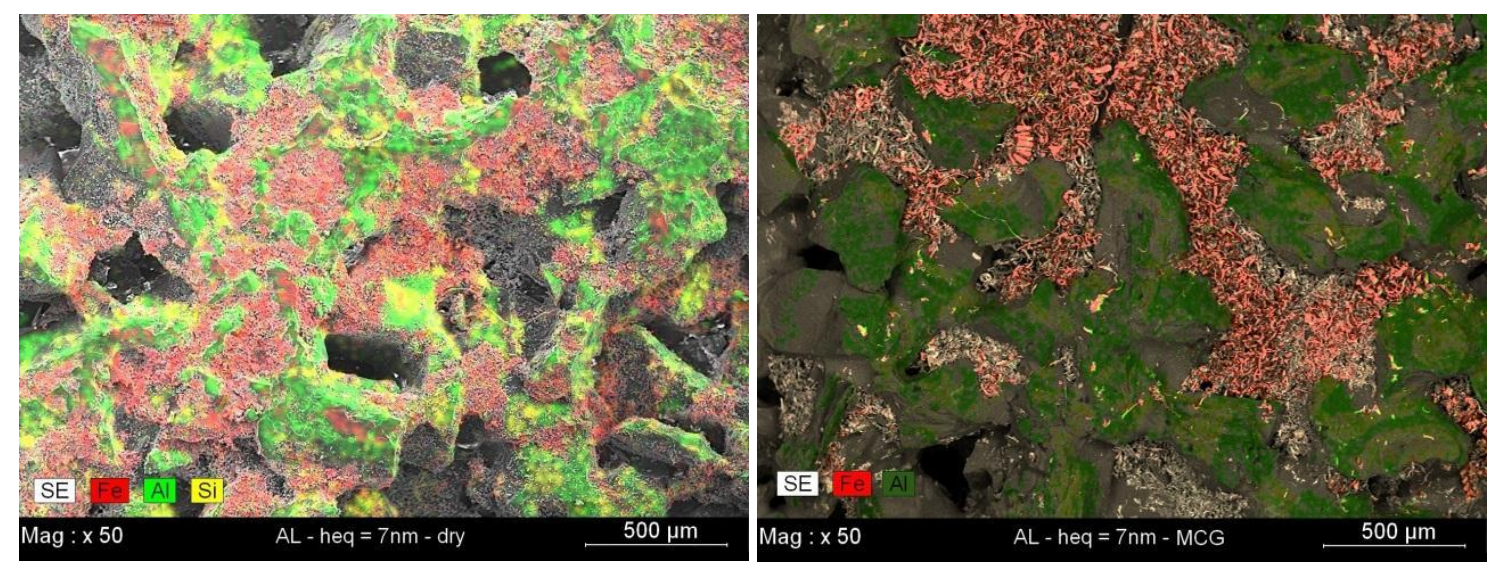

Figure 1. EDX analysis for AL with $h_{e q}=7 \mathrm{~nm}$ : Left, Dry grinding; Right, MCG grinding 
Click here to download Figure: Figure 11.docx

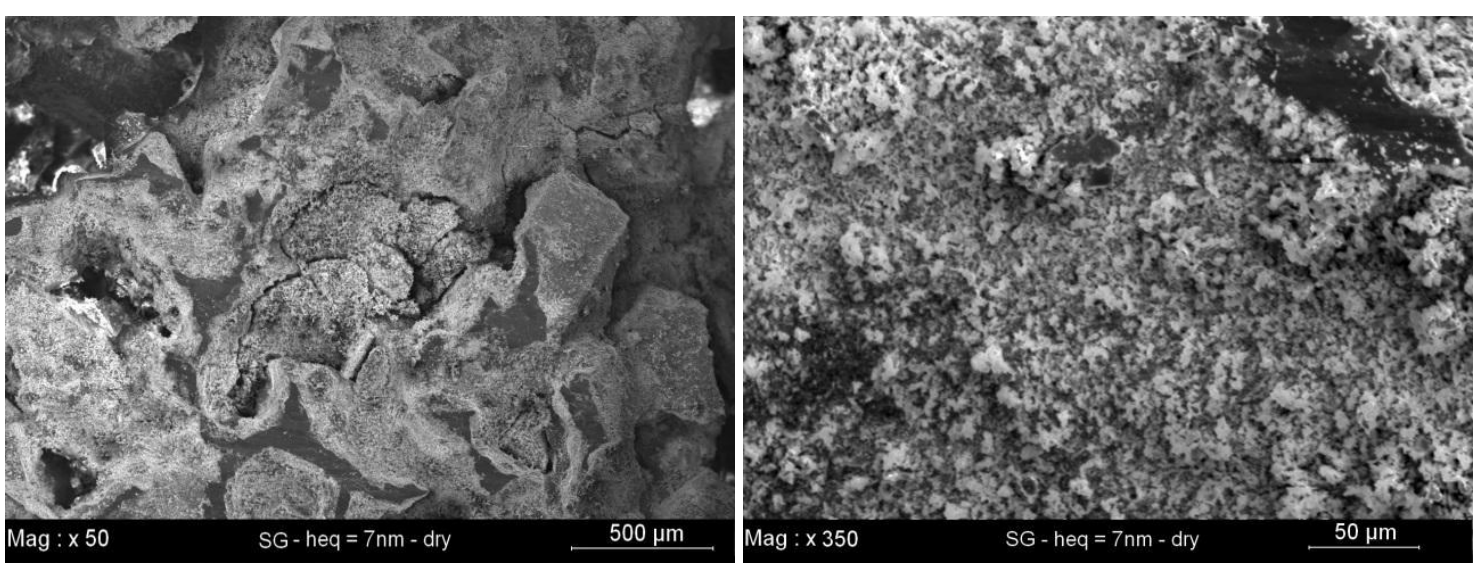

Figure 1. Globular steel debris in dry conditions for SG with $h_{e q}=7 \mathrm{~nm}$ : Left, 50x; Right, 350x 
Figure 12

Click here to download Figure: Figure 12.docx
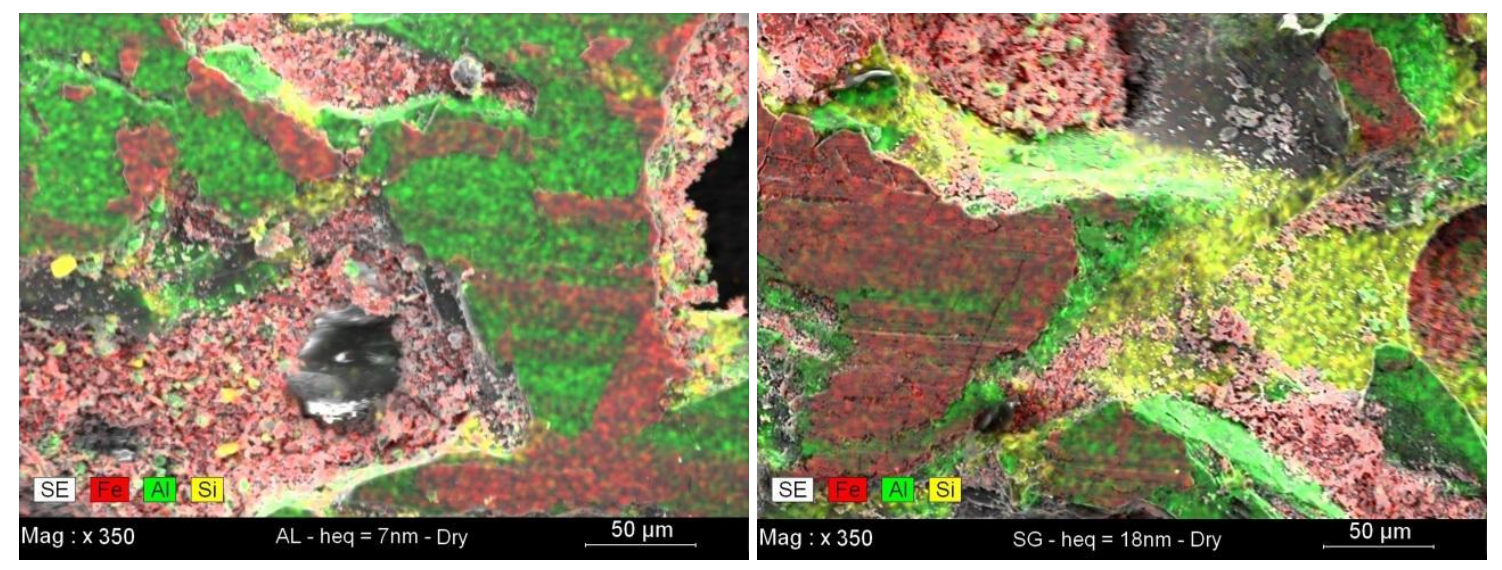

Figure 1. Steel layer formation under dry conditions: Left, AL $h_{e q}=7 \mathrm{~nm}$; Right, SG $h_{e q}=18 \mathrm{~nm}$ 
Figure 13

Click here to download Figure: Figure 13.docx
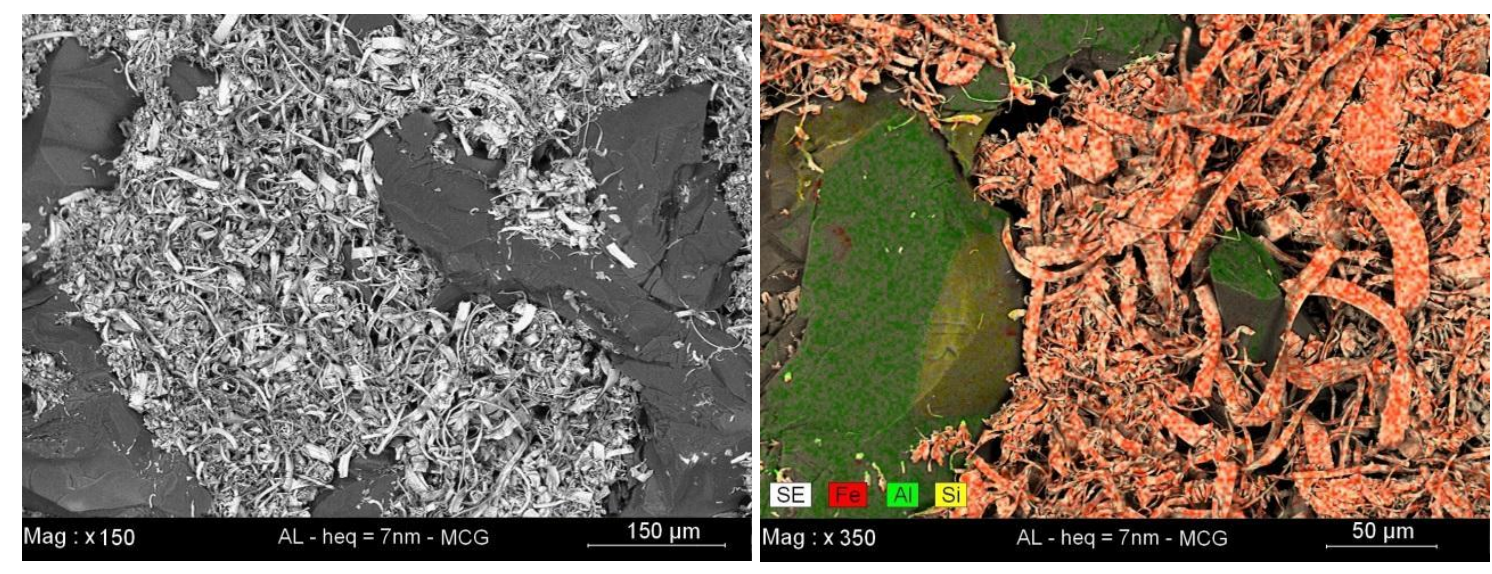

Figure 1. Acicular steel debris in MCG conditions for AL with $h_{e q}=7 \mathrm{~nm}$ : Left, 150x Right-350x 
Figure 14

Click here to download Figure: Figure 14.docx
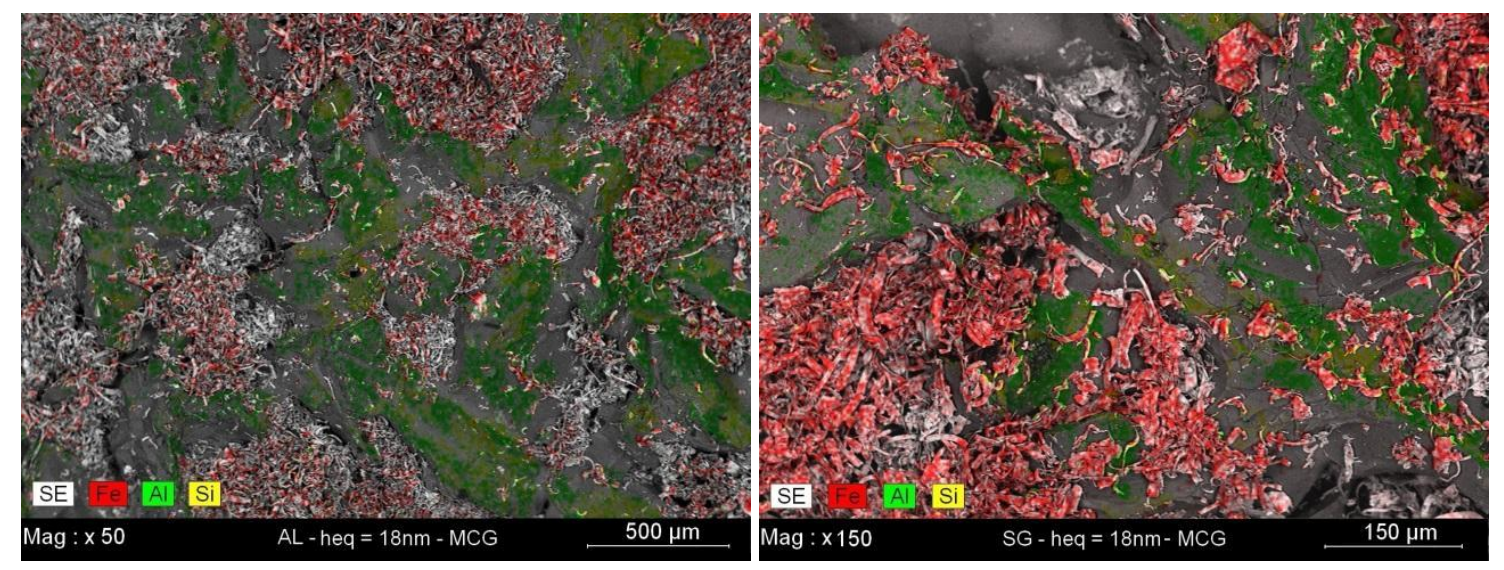

Figure 1. Steel wear debris in MCG conditions for $h_{e q}=18 \mathrm{~nm}$ : Left, AL; B, SG 
Click here to download Table: Table 1.docx

\begin{tabular}{|c|c|c|c|c|c|c|}
\hline $\begin{array}{l}\text { Cooling } \\
\text { Condition }\end{array}$ & Test & $\begin{array}{c}Q_{w}^{\prime} \\
{\left[\mathrm{mm}^{3} / \mathbf{m m}\right.} \\
\mathrm{s}]\end{array}$ & $h_{e q}[\mathrm{~nm}]$ & $\begin{array}{c}v_{f} \\
{[\mathrm{~mm} / \mathrm{min}]}\end{array}$ & $v_{s}[\mathrm{~m} / \mathrm{s}]$ & $\begin{array}{c}V_{w}^{\prime} \\
{\left[\mathrm{mm}^{3} / \mathrm{mm}\right]}\end{array}$ \\
\hline \multirow{2}{*}{ DRY } & Test 1 & 0.17 & 7 & 2 & 24 & 125 \\
\hline & Test 2 & 0.42 & 18 & 5 & 24 & 125 \\
\hline \multirow{2}{*}{ MCG } & Test 1 & 0.17 & 7 & 2 & 24 & 125 \\
\hline & Test 2 & 0.42 & 18 & 5 & 24 & 125 \\
\hline
\end{tabular}

Table 1. Experimental work description. These tests have been repeated with two grinding wheels: 2A46I8VWEB2 (AL) and 30SA46I8VWEB2 (SG). 
Table 2

Click here to download Table: Table 2.docx

\begin{tabular}{|c|c|c|c|c|}
\hline \multirow{2}{*}{$\begin{array}{c}\% \text { Wear Flat } \\
\text { Areas }\end{array}$} & \multicolumn{2}{|c|}{$A L$} & \multicolumn{2}{|c|}{ SG } \\
\hline & Test 1 & Test 2 & Test 1 & Test 2 \\
\hline DRY & $3.30 \%$ & $0.93 \%$ & $2.04 \%$ & $1.41 \%$ \\
\hline MCG & $0.24 \%$ & $0.16 \%$ & $1.12 \%$ & $0.14 \%$ \\
\hline
\end{tabular}

Table 1. Mean value in of the percentage of wear flat areas on worn surfaces measured by optical microscope observations. 